\title{
The Role of Self-efficacy and Social Support in Emerging Adults' Physical Activity
}

Nicole M. Silva

Follow this and additional works at: https://researchrepository.wvu.edu/etd

\section{Recommended Citation}

Silva, Nicole M., "The Role of Self-efficacy and Social Support in Emerging Adults' Physical Activity" (2015). Graduate Theses, Dissertations, and Problem Reports. 6644.

https://researchrepository.wvu.edu/etd/6644

This Thesis is protected by copyright and/or related rights. It has been brought to you by the The Research Repository @ WVU with permission from the rights-holder(s). You are free to use this Thesis in any way that is permitted by the copyright and related rights legislation that applies to your use. For other uses you must obtain permission from the rights-holder(s) directly, unless additional rights are indicated by a Creative Commons license in the record and/ or on the work itself. This Thesis has been accepted for inclusion in WVU Graduate Theses, Dissertations, and Problem Reports collection by an authorized administrator of The Research Repository @ WVU. For more information, please contact researchrepository@mail.wvu.edu. 
The Role of Self-efficacy and Social Support in Emerging Adults' Physical Activity

\author{
Nicole M. Silva \\ Thesis submitted \\ to the Eberly College of Arts and Sciences \\ at West Virginia University \\ in partial fulfillment of the requirements for the degree of \\ Master of Science in \\ Psychology
}

\author{
Julie Hicks Patrick, Ph.D., Chair \\ Amy Fiske, Ph.D. \\ Amy L. Gentzler, Ph.D.
}

\begin{abstract}
Department of Psychology
\end{abstract}
Morgantown, West Virginia
2015

Keywords: Emerging adult, physical activity, self-efficacy, social support Copyright 2015 Nicole M. Silva 


\begin{abstract}
The Role of Self-efficacy and Social Support in Emerging Adults' Physical Activity
\end{abstract}

Nicole M. Silva

Emerging adulthood is a time where emerging adults develop health behaviors that persist throughout the life span (Barnett et al., 2014). However, only 55.4\% of emerging adults engage in the recommended amount of physical activity each week (U.S. Department for Health and Human Services, 2013). The current study examined two factors that are associated with physical activity, specifically self-efficacy and social support, in 403 ( $M$ age $=19.25, S D=1.12$ ) emerging adults. Linear regressions indicated that emerging adults who reported higher levels of general self-efficacy $(\beta=.13, p<.05)$, domain self-efficacy $(\beta=.33, p<.05)$, and support from the entire social network $(\beta=.50, p<.001)$ engaged in more physical activity. Support from the entire social network still accounted for a significant portion of the variance in physical activity when accounting for general or domain self-efficacy ( $\beta$ for support $=.48, p<.001$ and $.30, p$ $<.05$, respectively). The differential effects of source of support (i.e., family and friends) and type of support (i.e., esteem support, informational support, and companionship support) were also examined. Emerging adults who reported higher levels of support from family $(\beta=.22, p$ $<.001)$ and friends $(\beta=.33, p<.001)$ engaged in more physical activity. Although emerging adults reported receiving more esteem support from family $(M=2.95, S D=1.23)$ compared to friends $(M=2.74, S D=1.15)$, esteem support from friends $(\beta=.33, p<.001)$ had a larger effect on physical activity than esteem support from family $(\beta=.21, p<.05)$. 


\section{ACKNOWLEDGEMENTS}

I would like to thank Dr. Julie Hicks Patrick for her guidance, support, and helpful suggestions throughout this process. I would also like to thank my committee members, Dr. Amy Fiske and Dr. Amy Gentzler, for their useful suggestions. I would like to thank West Virginia University's Department of Psychology and the Institute on Coaching at McLean Hospital for the funding to support this project. Finally, I would like to thank my fiancé, my friends, and my family for their never-ending support throughout this process. 


\section{TABLE OF CONTENTS}

Title. i



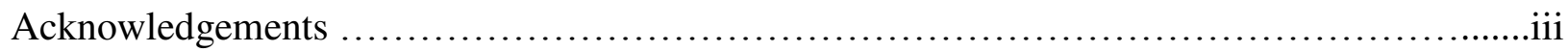

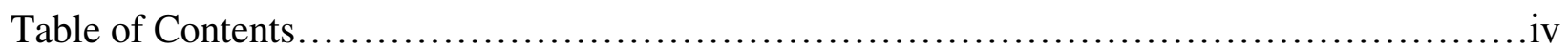

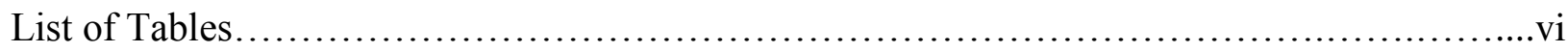



Method............................................................................

Results........................................................................11

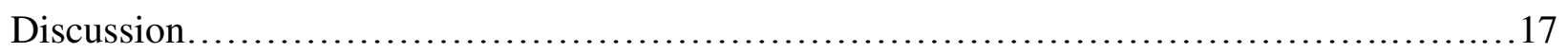

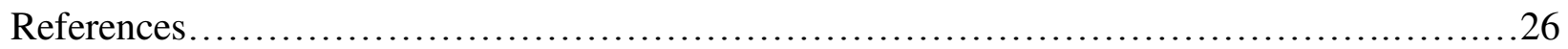



Appendix A: The Physical Activity Subscale of the HPLP-II.............................36

Appendix B: The Evaluation Questionnaire.......................................... 37

Appendix C: The Positive Social Influence Scale................................... 38

Appendix D: Positive Social Exchanges Scale........................................42

Appendix E: Negative Social Exchanges Scale $\ldots \ldots \ldots \ldots \ldots \ldots \ldots \ldots \ldots \ldots \ldots \ldots \ldots \ldots \ldots \ldots . \ldots \ldots$

Appendix F: The Godin Leisure Time Exercise Questionnaire............................44

Appendix G: Multiple Hierarchical Linear Regressions Predicting HPLP-II $(n=403) \ldots \ldots \ldots \ldots 45$

Appendix H: Multiple Hierarchical Linear Regressions Predicting HPLP-II $(n=81) \ldots \ldots \ldots . .57$

Appendix I: Multiple Hierarchical Linear Regressions Predicting Godin Leisure Time Exercise

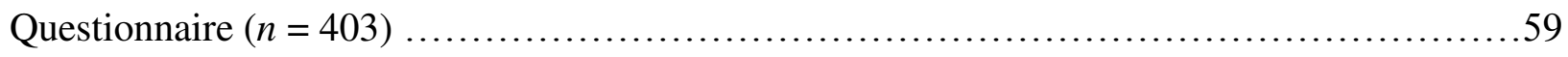


Appendix J: Multiple Hierarchical Linear Regressions Predicting Godin Leisure Time Exercise

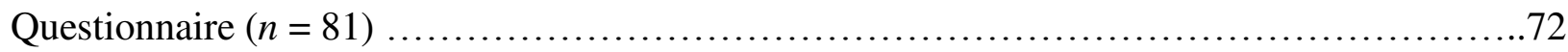
Appendix K: Multiple Hierarchical Liner Regressions Predicting HPLP-II and Controlling for

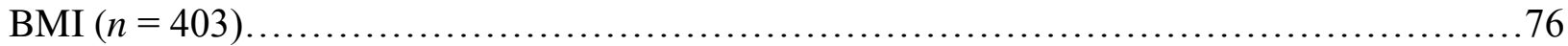




\section{LIST OF TABLES}

Table 1: Participants' Goals Pertaining to Physical Activity .................................30



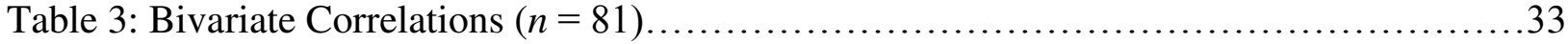


The Role of Self-efficacy and Social Support in Emerging Adults' Physical Activity

The benefits associated with engaging in physical activity are well known, ranging from an increased sense of well being to a decreased risk of developing Type 2 Diabetes and coronary heart disease (Kramer, Erickson, \& Colcombe, 2006). Despite these advantages, many emerging adults do not engage in adequate physical activity. Only $55.4 \%$ of emerging adults engage in the minimum recommended amount of 150 minutes of moderate-intensity physical activity (e.g., brisk walking) or 75 minutes of vigorous-intensity physical activity (e.g., jogging) each week (U.S. Department for Health and Human Services, 2013). This percentage is concerning because emerging adulthood is a time where adults develop health behaviors which persist throughout adulthood (Barnett et al., 2014). If emerging adults are not engaging in sufficient physical activity, there is a high likelihood that they will remain inactive in adulthood, which increases the potential for health risks later in the life span (American Heart Association, 2015; Barnett, Gauvin, Craig, \& Katzmarzyk, 2008). Therefore, it is important to identify factors that are associated with engaging in physical activity in emerging adulthood. If such factors are identified, it may be possible to increase the amount of physical activity emerging adults engage in, which may lead to healthier older cohorts as these individuals progress through the life span.

\section{Physical Activity Trends}

Many factors influence engagement in physical activity in emerging adulthood, including age, sex, race, and ethnicity. With respect to age, younger emerging adults report devoting more days per week toward stretching exercises while they also report engaging in higher levels of vigorous physical activity relative to older emerging adults (Buckworth \& Nigg, 2004). Males engage in more physical activity than females (Buckworth \& Nigg, 2004; Caspersen, Pereira, \& Curran, 2000). Individuals from African American, Hispanic, or Latino decent are more likely to 
be sedentary compared to Caucasians (Marcus et al., 2000; McNeill, Stoddard, Bennett, Wolin, \& Sorensen, 2012).

\section{Predictors of Physical Activity}

It is important to examine factors that contribute to emerging adults' engagement in physical activity because (a) physical activity in emerging adulthood is associated with physical activity later in the life span; (b) physical activity can reduce the incidence of new health conditions; (c) physical activity can reduce the severity of current health conditions' symptoms; and (d) physical activity can diminish current health conditions, such as Type 2 Diabetes (Barnett et al., 2014; U.S. Department for Health and Human Services, 2015). As such, theoretically-derived investigations of predictors are needed not only to advance the field, but to increase physical activity and quality of life in emerging adulthood.

Social cognitive theory. One theoretical model that has been investigated with physical activity is the social cognitive theory (Bandura, 1997). Social cognitive theory consists of multiple components related to behavior adoption such as self-efficacy, outcome expectations, goals, and impediments. One of the most-researched components of the social cognitive theory in regard to physical activity is self-efficacy (e.g., Brassington, Atienza, Perczek, DiLorenzo, \& King, 2002; George et al., 2013; Wallace et al., 2000). Self-efficacy can be divided into three components: general, domain, and task-related (Bandura, 1994). General self-efficacy is a person's belief that he or she is capable of accomplishing most behaviors. Domain self-efficacy is a person's belief that he or she is capable of engaging in most behaviors that are related to a certain behavioral domain (e.g., writing, physical activity). Task-related self-efficacy is a person's belief that he or she is capable of engaging in specific behaviors that are related to a behavioral domain (e.g., writing a paper, exercising for more than ten minutes; Bandura, 1997). 
Research examining the association between self-efficacy and physical activity indicates that domain and task-related self-efficacy are associated with physical activity in adulthood (Ayotte, Margrett, \& Patrick, 2013; Orsega-Smith, Payne, Mowen, Ho, \& Godbey, 2007). In regard to emerging adulthood, research indicates that domain self-efficacy is associated with physical activity. Sylvia-Bobiak and Caldwell (2006) assessed 874 undergraduates' (92\% of sample $18-21$ years old) domain self-efficacy and physical activity during their leisure activities. Results indicated that domain self-efficacy was positively associated with physical activity during leisure time activities. Similarly, Wallace and colleagues (2000) examined physical activity engagement and levels of domain self-efficacy in 937 undergraduates $(M$ age $=$ 22.0 years, $S D=5.6$ ). Results indicated that undergraduates who had higher levels of domain self-efficacy engaged in more physical activity. However, to our knowledge, research has not examined the effects of general self-efficacy or task-related self-efficacy on emerging adults' engagement in physical activity.

In addition to self-efficacy, the social cognitive theory emphasizes other factors that influence the adoption of behaviors, such as social support (Bandura, 1997). However, social support is often overshadowed in the physical activity literature by self-efficacy (Williams et al., 2008). Research indicates that social support influences self-efficacy and physical activity in emerging adulthood, therefore, it should not be overlooked in the literature. Rovniak, Anderson, Winett, and Stephens (2002) examined social support from friends, domain self-efficacy, and physical activity levels in 353 undergraduates $(M$ age $=19.56$ years, $S D=1.39)$. Results indicated that social support from friends was positively associated with domain self-efficacy, which was associated with physical activity. In addition, it is important to examine the effects of social support on emerging adults' physical activity levels because social support has been found 
to influence physical activity independent of self-efficacy in older adults (McAuley, Jerome, Elavsky, Marquez, \& Ramsey, 2003). However, this has not been examined in great detail in emerging adulthood.

Social support. Emerging adults spend more time communicating and with their friends compared to their family (Fraley \& Davis, 1997; Pugliese \& Okun, 2014). Thus, it may be possible that a specific source of support may be more influential in regard to physical activity. It may be possible that social support from family is more influential in regard to physical activity because family members tend to have each other's well being in mind. It may also be possible that social support from friends could be more influential because emerging adults spend more time with their friends compared to their family (Pugliese \& Okun, 2014).

However, the studies that have examined the effects of different sources of social support on physical activity report equivocal findings. Pugliese and Okun (2014) assessed 227 emerging adults' (age range 18 -22) self-reported number of attempts made by their parents and friends to engage in a physical activity. Results indicated that emerging adults were more likely to ignore their parents and engage in less physical activity when their parents encouraged physical activity compared to when their friends encouraged it. In comparison, results from Wallace and colleagues (2000) suggest that females are more likely to engage in physical activity if they receive support from their family while men are more likely to engage in physical activity if they receive support from their friends. Leslie and colleagues (1999) examined the amount of social support 2,729 college students (median age $=20$ years, range $15-76$ years) received from their family and friends and their engagement in physical activity. Results indicates that males who reported lower levels of social support from their friends and family were $45 \%$ and $48 \%$, respectively, more likely to be inactive compared to those who reported higher levels of social 
support. Females who reported lower levels of social support from their friends and family were $45 \%$ and $48 \%$, respectively, more likely to be inactive compared to those who reported higher levels of social support.

These results suggest that other factors related to the source of social support need to be examined in greater detail in order to clarify the associations among support from family, support from friends, and physical activity in emerging adulthood. It is possible that different relationships within the social network influence physical activity differently due to the functions of those relationships. The social support theory (Rook, 1994) suggests that three components of social relationships come together to influence engagement in behaviors: the quality, the content, and the evaluation of the network. The quality of the network consists of emerging adults' perception of the availability and frequency of contact with the individual members in the social network. The content of the relationship includes the different types of support emerging adults can receive (e.g., esteem, instrumental, and companionship; Chogahara, 1999) from the individual members within the network. The evaluation of the relationship includes emerging adults' satisfaction with the individual relationships.

When emerging adults perceive their relationships as available, supportive, and positive, they are more likely to engage in their health goals, such as physical activity (VonDras \& Madey, 2004). However, it is unclear whether one type of support (e.g., companionship, informational, esteem support) is more advantageous than others in regard to physical activity. Measures of social support for physical activity tend to group the different types of support into one composite measure. For example, the Social Support for Exercise Behavior Scale (Sallis, Grossman, Pinski, Patterson, \& Nader, 1987), which has been used in various studies (e.g., Leslie et al., 1999; Sylvia-Bobiak \& Caldwell, 2006; Wallace et al., 2000) combines items 
pertaining to companionship (e.g., "My friends have exercised with me"), informational (e.g., "My friends have discussed exercise with me"), and esteem support (e.g., "My friends have given me rewards for exercising") into one composite score. As such, it is possible that one type of support may be more advantageous than another in regard to physical activity.

Furthermore, it is not clear whether friends or family are more likely to engage in specific types of support in regard to physical activity. Because emerging adults spend more time with their friends and would rather be comforted by them compared to their parents (Fraley \& Davis, 1997; Pugliese \& Okun, 2014), it is possible that friends and family provide different types of support, which may influence emerging adults' physical activity levels differently.

\section{The Current Study}

Because emerging adulthood is a time where adults develop health behaviors that persist throughout adulthood and research indicates that this population is relatively sedentary (Barnett et al., 2014; U.S. Department for Health and Human Services, 2013), it is important to identify factors that are associated with physical activity. Thus, the purpose of this study was to develop a better understanding of the effects of general self-efficacy, domain self-efficacy, and social support on physical activity using the social cognitive theory and the social support theory as theoretical frameworks.

\section{Hypotheses and Exploratory Research Questions}

H1. Based on previous findings (e.g., Leslie et al., 1999; Wallace et al., 2000), it was hypothesized that emerging adults who report higher levels of support from the entire social network would engage in more physical activity. 
H2. Based on previous findings (e.g., Rovniak et al., 2002; Sylvia-Bobiak \& Caldwell, 2006), it was hypothesized that emerging adults who report higher levels of general self-efficacy or domain self-efficacy would engage in more physical activity.

E1. Research examining social support, self-efficacy, and physical activity in older adulthood suggests that social support is associated with physical activity when accounting for self-efficacy (McAuley et al., 2003). However, these associations have not been examined in emerging adulthood. Thus, this was explored to determine whether support from the entire social network is associated with physical activity when accounting for general self-efficacy or domain self-efficacy in emerging adulthood.

H3. Based on the social support theory (Rook, 1994), it was hypothesized that emerging adults who report their interactions with others as positive, and not negative, would engage in more physical activity.

E2. Due to equivocal findings in regard to the separate effects of support from family and friends on physical activity (e.g., Leslie et al., 1999; Pugliese \& Okun, 2014; Wallace et al., 2000), these associations were explored in greater detail.

E3. In order to understand the effects of different types of support (i.e., esteem, informational, and companionship) from the entire social network on physical activity, the influence of individual types of support for physical activity were examined.

E4. In order to understand the different types of social support friends and family offer in regard to physical activity, the associations among the types of support for physical activity (i.e., esteem, informational, and companionship) and source (i.e., family and friend) were examined.

\section{Method}

\section{Procedure and Participants}


Participants were recruited using a research participation system, which was available to students enrolled in psychology courses at a Mid-Atlantic university. All data $(n=1,043)$ were collected using an online survey tool and participants received course credit as compensation. In order to detect random response patterns, participants were required to correctly answer five out of eight response integrity checks. These checks consisted of directions such as "check 'very good"" or "mark the third option to show that you are reading all of the items." Two hundred and three participants did not correctly answer five response integrity checks and were excluded from the analyses. Participants were also instructed to list three to five short-term goals that they had for the upcoming year and to indicate which short-term goal was most important to them. The open-ended short-term goal responses were examined and 407 participants who did not list a physical activity goal (e.g., work out more or start running every day) were excluded from the analyses (see Table 1 for a condensed version of the physical activity goals that were listed). The 407 excluded participants engaged in less physical activity, $t(831)=-4.0, p<.001$, but reported higher levels of general self-efficacy, $t(827)=2.10, p<.05$. They did not differ in gender, $t(818)$ $=-0.46, p=.64$, or reported frequency of social support, $t(818.14)=-1.88, p=.06$. In addition, three participants were excluded because they reported that they completed the survey previously, three were excluded because they were underage and did not have parental consent, 12 participants were excluded due to being multivariate outliers, and 12 participants were excluded due to being older than 24, which resulted in a final sample of 403 participants.

In order to determine whether the sample size was sufficient to detect a medium-sized effect, post hoc power analyses were conducted using G*Power. Results indicated that 403 participants would provide sufficient power (.99) to detect a medium-sized effect in a multiple hierarchical linear regression with six predictors at $p<.05$. Results also indicated that 403 
participants would provide sufficient power (.99) to detect a medium-sized effect in a 2 x 3 repeated-measures ANOVA at $p<.05$.

Of the 403 participants $(M$ age $=19.25, S D=1.12$, Range $18-23), 330$ were female (81.9\%). In regard to race, $377(93.5 \%)$ participants identified as White or Caucasian, eight (2.0\%) participants identified as African American or Black, five (1.2\%) participants identified as Native Hawaiian, Pacific Islander, or Asian, and five (1.2\%) participants identified as having two or more race. In regard to highest level of education, 168 participants (41.7\%) earned a high school diploma or a G.E.D., 217 participants (53.8\%) earned some college credit or technical training, eight participants $(2.0 \%)$ earned a Bachelor's degree, and two participants $(0.5 \%)$ earned more than a Bachelor's degree.

\section{Measures}

Demographics. Participants indicated their age, race $(0=$ White, $1=$ African American, $2=$ American Indian, $3=$ Native Hawaiian, $4=$ Two or more races and $5=$ Other), education, and sex (0 for male and 1 for female).

Physical Activity. The Health-Promoting Lifestyle Profile-II (HPLP-II; Walker, Sechrist, \& Pender, 1995) physical activity subscale (8 items; see Appendix A) was used to assess participants' physical activity levels. Participants indicated whether they engaged in certain physical activity behaviors such as following a planned exercise program or getting exercise during usual daily activities. Responses could range from 1 (never) to 4 (routinely) and average scores across items were created $(M=2.10, S D=0.64, \alpha=.82)$.

Self-efficacy. The Evaluation Questionnaire (adapted from Mehta, 2008; Nurmi, 1994; 6 items; see Appendix B) was used to assess participants' general and domain self-efficacy in regard to their future goals. Participants indicated how much they agreed with a range of 
statements such as being determined to fulfill their goals or whether there were barriers that may have prevented them from achieving their future goals. Responses could range from 1 (strongly disagree) to 6 (strongly agree). The item that pertained to barriers was reverse coded and average scores across items were created $(M$ general self-efficacy $=4.81, S D=0.61 ; M$ domain self-efficacy $=4.83, S D=0.65)$. Because the variable was negatively skewed, participants' scores were reverse coded, logarithmic scores were computed, and scores were multiplied by -1 $(M$ general self-efficacy $=0.32, S D=0.11, \alpha=.75 ; M$ domain self-efficacy $=0.31, S D=0.65, \alpha$ $=.77)$.

Social support. The Positive Social Influence Scale (Chogahara, 1999; 30 items; see Appendix C) was used to assess the frequency of support for physical activity participants received from their social network. Participants indicated how often in the past year their family and friends, separately, provided companionship support (e.g., promised to engage in physical activity), informational support (e.g., explained why physical activity is important to improving health), and esteem support (e.g., praised superior physical activity level). Responses could range from 0 (never) to 4 (very often) and average scores across items were created for support from the entire social network $(M=2.73, S D=0.84, \alpha=.93)$, support from family $(M=2.64, S D=$ $0.96, \alpha=.91)$, support from friends $(M=2.82, S D=0.93, \alpha=.91)$, companionship support from the entire social network $(M=2.89, S D=0.95, \alpha=.87)$, informational support from the entire social network $(M=2.45, S D=0.93, \alpha=.86)$, and esteem support from the entire social network $(M=2.85, S D=1.11, \alpha=.92)$.

Social Exchanges. The Positive Social Exchanges Scale (Newsom, Rook, Nishishiba, Sorkin, \& Mahan, 2005; 12 items; see Appendix D) was used to assess the frequency of positive social exchanges participants received in the past month from their social network. Examples of 
positive social exchanges include receiving helpful advice and being helped with an important task that the participant could not do alone. Responses could range from 1 (never) to 5 (very often) and average scores across items were computed $(M=3.72, S D=0.72)$. Because the variable was negatively skewed, participants' scores were reverse coded, square root scores were computed, and scores were multiplied by $-1(M=1.06, S D=0.38, \alpha=.91)$.

The Negative Social Exchanges Scale (Newsom et al., 2005; 12 items; see Appendix E) was used to assess the frequency of negative social exchanges participants received in the past month from their social network. Examples of negative social exchanges include being left out of activities participants would have enjoyed or being asked for too much help. Responses could range from 1 (never) to 5 (very often) and average scores across items were computed $(M=2.29$, $S D=0.65)$. Because the variable was positively skewed, square root scores were computed $(M=$ $0.34, S D=0.12, \alpha=.92)$.

See Appendix F for an additional measure that was proposed but not included in the analyses.

\section{Results}

\section{Preliminary Analyses}

The data were first inspected for missing values. Overall, there were 38 missing values: 8 for age (1.9\% of the data), 7 for race (1.7\% of the data), 6 for sex (1.4\% of the data), 4 for positive social exchanges ( $0.9 \%$ of the data), 2 for general self-efficacy $(0.4 \%$ of the data), 6 for negative social exchanges $(1.4 \%$ of the data), and 5 for positive social exchanges $(1.2 \%$ of the data). The data were then examined for univariate outliers, which were not present in the data. To assess whether the data satisfied the assumptions of linear regression, the data were examined for linearity via scatterplots. Bivariate correlations were also examined and results indicated that 
sex, age, and negative social exchanges were not associated with physical activity at the bivariate level (see Table 2). To examine the assumptions of multicollinearity, multivariate outliers, and homoscedasticity of residuals, a linear regression was conducted where the variables were regressed onto Subject ID. Results indicated that multicollinearity was not present in the data (variance inflation factor $<4$ and tolerance value $>0.4$; Tabachnick \& Fidell, 2013). However, results indicated that 12 multivariate outliers (Mahalanobis distance scores $>26.12$ ) were present in the data. These outliers were deleted to ensure the accuracy of the results. Finally, the P-P plot of standardized residuals was examined and results indicated that slight heteroscedasticity was present in the data. Although heteroscedasticity can increase the probability of Type I error, Osborne and Waters (2002) suggest that slight heteroscedasticity has little effect on significance tests. An additional assumption, sphericity, was examined in regard to the $2 \times 3$ repeatedmeasures ANOVA. Results indicated that the assumption was met (Mauchly's W=.914).

\section{Results}

Previous research indicates that sex, race, and age influence the amount of physical activity emerging adults engage in (Buckworth \& Nigg, 2004; McNeill et al., 2012). However, due to the limited variability within these variables they were not included in the following analyses.

In regard to Hypothesis 1, a linear regression was conducted to determine whether participants who reported higher levels of support from the entire social network engaged in more physical activity. The overall model was significant, $F(1,397)=139.17, p<.001$. Support from the entire social network accounted for $25.8 \%$ of the variance in physical activity. Examination of the standardized beta indicated that emerging adults who reported higher levels of support $(\beta=.50, p<.001)$ engaged in more physical activity, which supports Hypothesis 1 . 
In regard to Hypothesis 2 and Exploratory Question 1, a multiple hierarchical linear regression was conducted to determine whether emerging adults who reported higher levels of general self-efficacy engaged in more physical activity and whether support from the entire social network is associated with physical activity when accounting for general self-efficacy. General self-efficacy was included in Step 1, was regressed onto physical activity, and accounted for $4.2 \%$ of the variance in physical activity, $F \Delta(1,396)=18.34, p<.001$. Examination of the standardized beta indicated that emerging adults who reported higher levels of general selfefficacy engaged in more physical activity $(\beta=.13, p<.05)$, which supports Hypothesis 2 . Next, support from the entire social network was included in Step 2 and was regressed onto physical activity. The overall model was significant, $F(2,395)=75.10, p<.001$. Support from the entire social network accounted for an additional $23.1 \%$ of the variance in physical activity, $F \Delta(1,385)$ $=126.06, p<.001$. Examination of the standardized betas indicated that emerging adults who reported higher levels of general self-efficacy $(\beta=.13, p<.05)$ and emerging adults who reported higher levels of support from the entire network $(\beta=.48, p<.001)$ engaged in more physical activity. These results contribute to Exploratory Question 1 and indicate that social support is associated with physical activity, even when accounting for general self-efficacy in emerging adulthood.

In regard to Hypothesis 3, a linear regression was conducted to determine whether emerging adults who perceived their exchanges with the social network as positive, and not negative, engaged in more physical activity. Positive social exchanges and negative social exchanges were regressed onto physical activity. The overall model was significant, $F(2,394)=$ $7.91, p<.001$ and the variables accounted for $3.4 \%$ of the variance in physical activity. Examination of the standardized betas indicated that negative social exchanges did not 
significantly account for variance in physical activity $(\beta=.00, p=.91)$. However, emerging adults who perceived their interactions with others as positive $(\beta=.19, p<.001)$ engaged in more physical activity, which supports Hypothesis 3.

In regard to Exploratory Question 2, a linear regression was conducted to examine the separate effects of reported support from family and reported support from friends on physical activity. Support from friends and family were regressed onto physical activity and the overall model was significant, $F(2,396)=70.19, p<.001$. These variables accounted for $25.8 \%$ of the variance in physical activity. Examination of the standardized betas indicated that emerging adults who reported higher levels of support from their friends $(\beta=.33, p<.001)$ and emerging adults who reported higher levels of support from their family $(\beta=.22, p<.001)$ engaged in more physical activity. These results contribute to Exploratory Question 2 and indicate that social support from friends and family, separately, are associated with physical activity.

In regard to Exploratory Question 3, a linear regression was conducted to examine the separate effects of reported esteem support, informational support, and companionship support from the entire social network on physical activity. Esteem support, informational support, and companionship support from the entire social network were regressed onto physical activity and the overall model was significant, $F(3,395)=65.73, p<.001$. These variables accounted for $32.8 \%$ of the variance in physical activity. Examination of the standardized betas indicated that informational support from the entire social network did not significantly account for variance in physical activity $(\beta=-.05, p=.28)$. However, emerging adults who reported higher levels of esteem support $(\beta=.51, p<.001)$ and emerging adults who reported higher levels of companionship support $(\beta=.14, p<.05)$ engaged in more physical activity. These results contribute to Exploratory Question 3 and indicate that emerging adults who reported higher 
levels of esteem support and companionship support from the entire social network engaged in more physical activity.

In regard to Exploratory Question 4, a 2 x 3 repeated-measures ANOVA was conducted to determine whether emerging adults reported receiving higher levels of esteem social support, informational social support, or companionship social support in regard to physical activity from their family or friends. Results indicated that the interaction between type of support and source was significant, $F(2,794)=263.84, p<.001, \eta^{2}=.37$. Further examination revealed that emerging adults reported receiving higher levels of esteem support from family $(M=2.95, S D=$ 1.23) than from friends $(M=2.74, S D=1.15)$, reported receiving higher levels of companionship support from friends $(M=2.32, S D=1.12)$ than from family $(M=2.45, S D=$ 1.18), and reported receiving higher levels of informational support from family $(M=2.51, S D=$ 1.08) than from friends $(M=2.40, S D=1.05)$. These results contribute to Exploratory Question 4 and suggest that perceived differences are present in regard to the type of support family and friends engage in.

To examine the effects of esteem support from family, companionship support from family, informational support from family, esteem support from friends, companionship support from friends, and information support from friends on physical activity, a linear regression was conducted. These variables were regressed onto physical activity and the overall model was significant, $F(6,391)=32.25, \mathrm{p}<.001$ and accounted for $32.1 \%$ of the variance in physical activity. Examination of the standardized betas indicated that companionship support from family $(\beta=.06, p=.27)$, informational support from family $(\beta=-.01, p=.87)$, companionship support from friends $(\beta=.10, p=.08)$, and informational support from friends $(\beta=-.05, p=.36)$ did not significantly account for variance in physical activity. However, esteem support from 
family $(\beta=.21, p<.05)$ and esteem support from friends $(\beta=.33, p<.001)$ were positively associated with physical activity. These results indicate that emerging adults who reported higher levels of esteem support from family and emerging adults who reported higher levels of esteem support from friends engaged in more physical activity.

\section{Post Hoc Analyses}

Because the previous self-efficacy analyses examined the effects of general self-efficacy (i.e., a person's belief that he or she is capable of accomplishing most behaviors) on physical activity, post hoc analyses were conducted to examine the effects of domain self-efficacy (i.e., a person's belief that he or she is capable of accomplishing most physical activity behaviors) on physical activity. In order to accomplish this, the open-ended short-term goal responses were reexamined and participants who did not list a physical activity as their most important goal were excluded. This resulted in a final sample of 81 participants. The excluded participants engaged in less physical activity, $t(401)=-2.16, p<.05$, and consisted of more males, $t(173.24)=-3.10, p$ $<.05$. The excluded group did not differ in the amount of social support they received from the entire social network, $t(397)=-0.95, p=.34$, or general self-efficacy $t(423)=0.57, p=.56$.

Of the 81 participants $(M$ age $=19.22, S D=1.04), 73(90.1 \%)$ were female and 76 (93.8\%) identified as White or Caucasian (see Table 3 for bivariate correlations). In order to determine whether the sample size was sufficient to detect a medium-sized effect, post hoc power analyses were conducted using $\mathrm{G}^{*}$ Power. Results indicated that 81 participants would provide sufficient power (.87) to detect a medium-sized effect in a regression with two predictors at $p<.05$.

Results. In regard to Hypothesis 2 and Exploratory Question 1, a multiple hierarchical linear regression was conducted to determine whether emerging adults who reported higher 
levels of domain self-efficacy engaged in more physical activity and whether support from the entire social network was associated with physical activity when accounting for domain selfefficacy. Domain self-efficacy was included in Step 1, was regressed onto physical activity, and accounted for $10.3 \%$ of the variance in physical activity, $F \Delta(1,79)=10.21, p<.05$.

Examination of the standardized beta indicated that emerging adults who reported higher levels of domain self-efficacy engaged in more physical activity $(\beta=.33, p<.05)$, which supports Hypothesis 2. Next, support from the entire social network was included in Step 2 and was regressed onto physical activity. The overall model was significant, $F(2,78)=9.67, \mathrm{p}<.001$. Support from the entire social network accounted for an additional $8.4 \%$ of the variance in physical activity, $F \Delta(1,78)=8.20, p<.001$. Examination of the standardized betas indicated that emerging adults who reported higher levels of domain self-efficacy $(\beta=.23, p<.05)$ and emerging adults who reported higher levels of support from the entire network $(\beta=.30, p<.05)$ engaged in more physical activity. These results contribute to Exploratory Question 1 and indicate that social support is associated with physical activity, even when accounting for domain self-efficacy levels in emerging adulthood.

See Appendices G, H, I, and J for additional proposed analyses that were not included in this document.

\section{Discussion}

Emerging adulthood is a time where emerging adults develop health behaviors that persist throughout adulthood (Barnett et al., 2014). However, only 55.4\% of emerging adults engage in the recommended amount of physical activity each week (U.S. Department for Health and Human Services, 2013). If emerging adults do not engage in physical activity, there is a high likelihood that they will remain inactive in adulthood, which increases the potential for health 
risks later in the life span (American Heart Association, 2015; Barnett et al., 2008). As such, the current study examined factors that are associated with physical activity, specifically selfefficacy and social support, in emerging adulthood.

\section{The social cognitive theory}

The social cognitive theory consists of multiple components that result in behavior adoption and the most researched component in regard to physical activity is self-efficacy (Bandura, 1997). To our knowledge, general self-efficacy (i.e., the belief that one can engage in most behaviors) has not been examined in regard to emerging adults' physical activity. Therefore, we examined whether emerging adults' general self-efficacy was associated with physical activity, in which we hypothesized that it would be. Results from the multiple hierarchical linear regression indicated that emerging adults who reported higher levels of general self-efficacy engaged in more physical activity, which supports Hypothesis 2. Although this association only accounted for $4.2 \%$ of the variance in physical activity, it suggests that emerging adults' beliefs that they are capable of accomplishing most behaviors are associated with physical activity.

Previous research suggests that domain self-efficacy (i.e., a person's belief that he or she is capable of accomplishing most physical activity behaviors) is positively associated with physical activity in emerging adulthood (Sylvia-Bobiak \& Caldwell, 2006; Wallace et al., 2000). In order to examine whether domain self-efficacy was associated with physical activity in the current study, a post hoc multiple hierarchical linear regression was conducted in which emerging adults who did not list a physical activity as their most important short-term goal were removed from the analysis. Results from the analysis supported previous research in which emerging adults who reported higher levels of domain self-efficacy engaged in more physical 
activity. Domain self-efficacy accounted for $10.3 \%$ of the variance in physical activity, which is a greater amount of variance accounted for compared to general self-efficacy.

It may be possible that general self-efficacy is the initial confidence emerging adults need in order to attempt physical activity while domain self-efficacy may be the enduring confidence emerging adults need to maintain those behaviors. As previously mentioned, general selfefficacy is a person's belief that he or she is capable of accomplishing most behaviors (Bandura, 1997). As such, emerging adults who have higher levels of general self-efficacy may be more likely to attempt a physical activity. When emerging adults successfully engage in the physical activity, their domain self-efficacy (i.e., belief that they capable of accomplishing most physical activity behaviors) increases. This increase in domain self-efficacy makes it more likely that they will engage in the physical activity at a later time (Bandura, 1997). Thus, making it possible that general self-efficacy is the initial confidence emerging adults need in order to engage in physical activity. However, this needs to be examined in greater detail in future research.

\section{Social support}

Previous research also suggests that another predictor of physical activity in emerging adulthood is social support. Specifically, emerging adults who report higher levels of social support engage in more physical activity (Pugliese \& Okun, 2014; Wallace et al., 2000). Thus, it was hypothesized that emerging adults who reported higher levels of social support from the entire social network would engage in more physical activity. Results from the linear regression supported Hypothesis 1. Social support from the entire social network accounted for $25.8 \%$ of the variance in physical activity suggesting that social support has a strong effect on emerging adults' physical activity. 
Because the Positive Social Influences Scale (Chogahara, 1999) contains esteem, informational, and companionship support in regard to physical activity, there are multiple reasons as to why support from the entire social network accounted for $25.8 \%$ of the variance in physical activity. Specifically, the social network may reinforce emerging adults' physical activity or convince emerging adults that they possess the skills needed to master physical activity. These processes are apparent in the items pertaining to esteem support, specifically, being complimented, affirmed, and praised for their skills and efforts in regard to a physical activity. Emerging adults who are persuaded that they possess the skills needed to engage and sustain physical activity are going to place greater emphasis on the activities compared to emerging adults who are not persuaded (Bandura, 1994). Furthermore, the social network may model physical activity, which is also apparent in the items pertaining to companionship support, specifically, making plans or teaming up to engage in physical activity together. When the social network models physical activity, they are providing a standard in which emerging adults can compare, judge, and adjust their behaviors accordingly if necessary. This modeling teaches emerging adults the skills that are required for successfully engaging in physical activity (Bandura, 1994).

Unfortunately, social support is usually overshadowed in the literature by self-efficacy although social support has been positively associated with self-efficacy and physical activity (Rovniak et al., 2002; Wallace et al., 2000). Furthermore, social support has been positively associated with physical activity when accounting for self-efficacy in adults (McAuley et al., 2003). To determine whether social support from the entire social network significantly accounted for variance in physical activity when accounting for general or domain self-efficacy, a multiple hierarchical linear regression and a post hoc multiple hierarchical linear regression 
were conducted. Results indicated that support from the entire social network significantly accounted for variance in physical activity when accounting for general or domain self-efficacy. These results, which contributed to Exploratory Question 1, indicate that social support is associated with emerging adults' physical activity levels. As such, social support should be examined in regard to physical activity in addition to self-efficacy in future research because researchers may be excluding an important predictor in regard to physical activity if they do not.

It is possible that a specific source of support may be more influential in regard to physical activity because emerging adults spend more time communicating and with their friends compared to their family (Fraley \& Davis, 1997; Pugliese \& Okun, 2014). The current study examined the separate effects of reported social support from family and friends on emerging adults' physical activity. A linear regression indicated that support from family and friends were positively associated with physical activity, which contributed to Exploratory Question 2. The standardized beta associated with friend support $(\beta=.33, p<.001)$ was greater than the standardized beta associated with family support $(\beta=.22, p<.001)$, suggesting that support from friends has a greater influence on emerging adults' physical activity relative to support from family. This may be due to selection and socialization of friendships in which emerging adults select friends who are similar to themselves and reinforce those behaviors (Steglich, Snijders, \& Pearson, 2010). Although results from Barnett et al. (2014) indicated that participants' physical activity was not associated with their nominated friends' physical activity, it is possible that friends' physical activity are still associated with one another because not all of the participants within Barnett and colleagues' (2014) study could select their friends' names from the database that the researchers used. Thus, it is possible that emerging adults form friendships based upon similar physical activity levels and reinforce those behaviors, making it more likely that this 
support has a greater impact on emerging adults' physical activity levels compared to family members. Furthermore, because our sample consisted of emerging adults that were enrolled in college, it is possible that these emerging adults lived with their friends, making support from friends more prominent in their recall. However, we did not collect this type of information in order to assess this association.

One reason as to why support from friends had a greater influence on emerging adults' physical activity relative to support from family may be because friends and family engage in different types of support (i.e., informational, companionship, and esteem support), which has differential effects on emerging adults' physical activity. A 2 x 3 repeated-measures ANOVA was conducted to determine whether there were reported differences in the types of social support emerging adults receive. Results from the ANOVA indicated that emerging adults reported receiving higher levels of esteem and informational support from their family while they also reported receiving higher levels of companionship support from their friends. These reported differences may be because emerging adults spend more time with their friends relative to their family members (Pugliese \& Okun, 2014), thus, making it possible that emerging adults have more opportunities to engage in physical activity with their friends compared to the opportunities to engage in physical activity with their family.

Although differences in the reported levels of support from family and friends are intriguing, the repeated-measures ANOVA could not examine their effects on emerging adults' physical activity. As such, a linear regression was conducted in which the effects of esteem support, companionship support, and informational support from family and friends, separately, were examined. Results indicated that emerging adults who reported higher levels of esteem support from family and esteem support from friends engaged in more physical activity. Similar 
to previous results, the standardized beta associated with esteem support from friends $(\beta=.33, p$ $<.001)$ was greater than the standardized beta associated with esteem support from family $(\beta$ $=.21, p<.05)$. These results suggest that although emerging adults report receiving higher levels of esteem support from their family, esteem support from friends exhibits a stronger association with physical activity. As previously stated, esteem support contains items that pertain to being complimented, affirmed, and praised for skills and efforts in regard to a physical activity (Chogahara, 1999). As such, although emerging adults report receiving higher levels of esteem support from family, esteem support from friends may be more influential because emerging adults may internalize friends' praises more because emerging adults spend more time with their friends compared to their family (Pugliese \& Okun, 2014). Furthermore, it is possible that because emerging adults reported receiving higher levels of companionship from their friends (i.e., emerging adults reported teaming up and engaging in physical activity with their friends more), it is possible that friends are more knowledgeable of their skills within physical activity, making their praises more valid than their families.

\section{Limitations and Future Directions}

Results should be interpreted in the context of the following limitations. The sample that was utilized for this study was predominately Caucasian females and all were enrolled in psychology courses at a Mid-Atlantic university. It is possible that these results cannot be generalized to other emerging adult populations due to the unique characteristics of our college sample. Future research should examine these processes in a more diverse sample of emerging adults. Future research should also examine these processes in a sample of emerging adults who are not enrolled in college courses. It is possible that the data we obtained is specific to emerging adults enrolled in college because these individuals may be more likely to move out and spend 
more time with their friends in comparison to emerging adults who are not enrolled in college. Thus, it is possible that differential effects of source and type of support would emerge within this specific sample.

There was limited variability within the variables of sex and race in our sample. Previous research indicates that these variables influence self-efficacy and physical activity (Caspersen et al., 2000; Marcus et al., 2000; McNeill et al., 2012). However, these associations could not be appropriately examined or accounted for due to limited variability. Future research should examine the effects of sex and race on emerging adults' physical activity.

Our measures of physical activity, self-efficacy, positive social exchanges, negative social exchanges, and perceived social support were self-reports. It is possible that the scores we obtained were not accurate due to social desirability. In addition, the title of the study contained the words "health-related behaviors." It is possible that participants were primed to answer in specific ways (i.e., answer that they engage in more physical activity than what is accurate) within the questionnaires. Furthermore, there are no known studies that have examined whether self-reported physical activity from the HPLP-II accurately assesses physical activity engagement. It is possible that this subjective measurement of physical activity is not as accurate as objective measures of physical activity.

Although the post hoc analyses were conducted in order to examine the effects of domain self-efficacy on physical activity, it is possible that the results were skewed due to removal of specific participants. Specifically, participants who did not list a physical activity as their most important short-term goal were removed from the analyses. This exclusion may have resulted in a significant finding because the emerging adults who were excluded engaged in less physical activity. 
Due to the cross-sectional nature of the study, causal associations among self-efficacy, social support, and physical activity cannot be examined. Furthermore, the direction of effects cannot be interpreted. Specifically, it is possible that being physically active results in praises (i.e., esteem support) from the members of the social network. It is also possible that the presence of social support from members of the social network contributes to emerging adults' physical activity levels. As such, future research should implement longitudinal or crosssequential research designs to examine the causal associations among these variables.

Overall, the findings from the current study suggest that self-efficacy and social support are important predictors of emerging adults' physical activity. These findings should be examined in greater detail in future research to determine whether these associations are still significant after accounting for the limitations within the current study. If self-efficacy and social support are still associated with emerging adults' physical activity, it is possible to create interventions that target emerging adults' self-efficacy and social support in order to increase their engagement in physical activity. If successful, the physical activity behaviors will be carried throughout adulthood, which may lead to healthier older cohorts as these individuals progress through the life span. 


\section{References}

American Heart Association (2015). Physical activity improves quality of life. Retrieved from http://www.heart.org/HEARTORG/GettingHealthy/PhysicalActivity/StartWalking/Physi cal-activity-improves-quality-of-life_UCM_307977_Article.jsp

Ayotte, B. J., Margrett, J. A., \& Patrick, J. H. (2013). Dyadic analysis of self-efficacy and perceived support: The relationship of individual and spousal characteristics with physical activity among middle-aged and young-older adults. Psychology and Aging, 28(2), 555-63. doi:10.1037/a0032454

Bandura, A. (1994). Self-efficacy. In Encyclopedia of human behavior. Academic Press.

Bandura, A. (1997). Self efficacy: The exercise of control. New York, NY: W.H. Freeman and Company.

Barnett, N. P., Ott, M. Q., Rogers, M. L., Loxley, M., Linkletter, C., \& Clark, M. A. (2014). Peer associations for substance use and exercise in a college student social network. Health Psychology, 33(10), 1134-1142. doi:10.1037/a0034687

Barnett, T. A., Gauvin, L., Craig, C. L., \& Katzmarzyk, P. T. (2008). Distinct trajectories of leisure time physical activity and predictors of trajectory class membership: A 22 year cohort study. International Journal of Behavioral Nutrition and Physical Activity, 5. doi:10.1186/1479-5868-5-57

Brassington, G. S., Atienza, A. A., Perczek, R. E., DiLorenzo, T. M., \& King, A. C. (2002). Intervention-related cognitive versus social mediators of exercise adherence in the elderly. American Journal of Preventive Medicine, 23(2), 80-86. doi:10.1016/S07493797(02)00477-4

Buckworth, J., \& Nigg, C. (2004). Physical activity, exercise, and sedentary behavior in college 
students. Journal of American College Health, 53(1), 28-34. doi:10.3200/JACH.53.1.28-34

Caspersen, C. J., Pereira, M. A., \& Curran, K. M. (2000). Changes in physical activity patterns in the United States, by sex and cross-sectional age. Medicine and Science in Sports and Exercise, 32(9), 1601-1609. doi:10.1097/00005768-200009000-00013

Chogahara, M. (1999). A multidimensional scale for assessing positive and negative social influences on physical activity in older adults. Journal of Gerontology, 54B(6), S356-S367. doi:10.1093/geronb/54B.6.S356

Fraley, R. C., \& Davis, K. E. (1997). Attachment formation and transfer in young adults' close friendships and romantic relationships. Personal Relationships, 4, 131-144. doi:10.1111/j.1475-6811.1997.tb00135.x

George, M., Eys, M. A., Oddson, B., Roy-Charland, A., Schinke, R. J., \& Bruner, M. W. (2013). The role of self-determination in the relationship between social support and physical activity intentions. Journal of Applied Social Psychology, 43(6), 1333-1341. doi:10.1111/jasp.12142

Godin, G., \& Shephard, R. J. (1997). Godin leisure-time exercise questionnaire. Medicine and Science in Sports and Exercise, 26(6), S36-38.

Kramer, A. F., Erickson, K. I., \& Colcombe, S. J. (2006). Exercise, cognition, and the aging brain. Journal of Applied Physiology, 101, 1237-1242. doi:10.1152/japplphysiol.00500.2006

Leslie, E., Owen, N., Salmon, J., Bauman, A., Sallis, J. F., \& Lo, S. K. (1999). Insufficiently active Australian college students: Perceived personal, social, and environmental influences. Preventive Medicine, 28(1), 20-27. doi:10.1006/pmed.1998.0375

Marcus, B. H., Forsyth, L. A. H., Stone, E. J., Dubbert, P. M., McKenzie, T. L., Dunn, A. L., \& 
Blair, S. N. (2000). Physical activity behavior change: Issues in adoption and maintenance. Health Psychology, 19(1), 32-41. doi:10.1037//0278-6133.19.1(Suppl.).32

McAuley, E., Jerome, G. J., Elavsky, S., Marquez, D. X., \& Ramsey, S. N. (2003). Predicting long-term maintenance of physical activity in older adults. Preventive Medicine, 37(2), 110-118. doi:10.1016/S0091-7435(03)00089-6

McNeill, L. H., Stoddard, A., Bennett, G. G., Wolin, K. Y., \& Sorensen, G. G. (2012). Influence of individual and social contextual factors on changes in leisure-time physical activity in working-class populations: Results of the Healthy Directions-Small Businesses Study. Cancer Causes Control, 23(9), 1475-1487. doi:10.1007/s10552-012-0021-z

Mehta, C. M. (2008). An examination of collectivist and individualistic young adult women's future goals and their evaluation. West Virginia University.

Newsom, J. T., Rook, K. S., Nishishiba, M., Sorkin, D. H., \& Mahan, T. L. (2005). Understanding the relative importance of positive and negative social exchanges: Examining specific domains and appraisals. Journal of Gerontology: Psychological Sciences, 60B(6), P304-P312. doi:10.1093/geronb/60.6.P304

Nurmi, J. (1994). The development of future-orientation in a life-span context. In Z. Zaleski (Ed.), Psychology of Future Orientation (pp. 63-74). Lublin, Poland: Towarzystwo Naukowe KUL.

Orsega-Smith, E. M., Payne, L. L., Mowen, A. J., Ho, C. H., \& Godbey, G. C. (2007). The role of social support and self-efficacy in shaping the leisure time physical activty of older adults. Journal of Leisure Research, 39(4), 705-727.

Osborne, J. W., \& Waters, E. (2002). Four assumptions of multiple regression that researchers should always test. Practical Assessment, Research, and Evaluation, 8(2), 1-5. 
Pugliese, J. A., \& Okun, M. A. (2014). Social control and strenuous exercise among late adolescent college students: Parents versus peers as influence agents. Journal of Adolescence, 37(5), 543-554. doi:10.1016/j.adolescence.2014.04.008

Rook, K. S. (1994). Assessing the health-related dimensions of older adults' social relationships. Annual Review of Gerontology and Geriatrics, 14, 142-181.

Rovniak, L. S., Anderson, E. S., Winett, R. A., \& Stephens, R. S. (2002). Social cognitive determinants of physical activity in young adults: A prospective structural equation analysis. Annals of Behavioral Medicine, 24(2), 149-156. doi:10.1207/S15324796ABM2402_12

Sallis, J. F., Grossman, R. M., Pinski, R. B., Patterson, T. L., \& Nader, P. R. (1987). The development of scales to measure social support for diet and exercise behaviors. Preventive Medicine, 16, 825-836.

Steglich, C. E. G., Snijders, T. A. B., \& Pearson, M. (2010). Dynamic networks and behavior: Separating selection from influence. Sociological Methodology, 40, 329-393. doi:10.1111/j.1467-9531.2010.01225.x

Sylvia-Bobiak, S., \& Caldwell, L. L. (2006). Factors related to physically active leisure among college students. Leisure Sciences, 28(1), 73-89. doi:10.1080/01490400500332728

Tabachnick, B. G., \& Fidell, L. S. (2013). Multilevel linear modeling. In Using multivariate statistics. (6th ed., pp. 837-914). New York, NY: Harper Collins.

VonDras, D. D., \& Madey, S. F. (2004). The attainment of important health goals throughout adulthood: An integration of the theory of planned behavior and aspects of social support. International Journal of Aging and Human Development, 59(3), 205-234.

Walker, S., Sechrist, K., \& Pender, N. (1995). The health-promoting lifestyle profile II. Omaha: University of Nebraska Medical Center, College of Nursing. 
Wallace, L. S., Buckworth, J., Kirby, T. E., \& Sherman, W. M. (2000). Characteristics of exercise behavior among college students: Application of social cognitive theory to predicting stage of change. Preventive Medicine, 31(5), 494-505.

doi:10.1006/pmed.2000.0736

Williams, D. M., Lewis, B. A., Dunsiger, S., Whiteley, J. A., Papandonatos, G. D., Napolitano, M. A., ... Marcus, B. H. (2008). Comparing psychosocial predictors of physical activity adoption and maintenance. Annals of Behavioral Medicine, 36(2), 186-194. doi:10.1007/s12160-008-9054-7

U.S. Department of Education (2015). Percentage of 18- to 24-year-olds enrolled in degreegranting institutions, by level of institution and sex and race/ethnicity of student: 1967 through 2012. Retrieved from http://nces.ed.gov/programs/digest/d13/tables/dt13_302.60.asp

United States Department of Health and Human Services (2013). Health behaviors of adults: United States 2008-2010. Vital and Health Statistics 10(257).

United States Department of Health and Human Services (2015).Physical activity and health: The benefits of physical activity. Retrieved from http://www.cdc.gov/physicalactivity/basics/pa-health/ 
Table 1

Participants' Goals Pertaining to Physical Activity

\begin{tabular}{ll}
\hline Goal & $\mathrm{N}(\%)$ \\
\hline Lose weight & $142(35.23)$ \\
Get in shape & $71(17.61)$ \\
Exercise more/be more active & $5613.89)$ \\
Exercise & $17(4.21)$ \\
Play a sport (e.g., soccer, rugby) & $13(3.22)$ \\
Gain weight/muscle & $12(2.97)$ \\
Maintain weight/body mass index & $11(2.72)$ \\
Start exercising & $11(2.72)$ \\
Run 5k/half marathon & $10(2.48)$ \\
Continue exercising & $6(1.48)$ \\
Increase endurance/stamina & \\
\hline
\end{tabular}


Table 2

Bivariate Correlations $(n=403$ )

1

2

34

45

6

$6 \quad 7$

1. Physical activity

2. General self-efficacy

$21 * * \quad-$

3. Support from entire social

$.50^{* *} \quad .16^{*} \quad-$

network

4. Support from family

$.42 * * \quad .14 * \quad .88 * * \quad-$

5. Support from friends

$\begin{array}{llll}.47 * * & .13 * & .88 * * & .56 * * \quad-\end{array}$

6. Esteem support from entire

$\begin{array}{lllll}.56 * * & .21 * * & .84 * * & .73 * * & .76 * * \quad-\end{array}$

social network

7. Informational support from

$.28 * * \quad .05$

$.81 * * \quad .72 * * \quad .72 * * \quad .49 * * \quad-$

entire social network

8. Companionship support from

$.41 * * \quad .12 *$

$.86 * *$

$.79 * *$

$.73 * *$

$.59 * *$

$.60 * * \quad-$

entire social network

9. Positive social exchanges

$.19 * *$

$.29 * *$

$.41 * *$

$.35^{* *}$

$.37 * * \quad .36 * *$

$.32 * * \quad .35 * * \quad-$ 


\begin{tabular}{|c|c|c|c|c|c|c|c|c|c|c|c|}
\hline 10. Negative social exchanges & -.06 & $-.23 * *$ & -.01 & .00 & -.02 & -.05 & .03 & .00 & $-.28 * *$ & - & \\
\hline 11. Age & -.02 & -.06 & -.03 & -.06 & .00 & -.03 & -.01 & -.03 & -.04 & -.09 & - \\
\hline 12. Race $(0=$ White, $1=$ African & $-.19 * *$ & .01 & -.09 & -.03 & $-.12 *$ & -.08 & -.06 & -.08 & -.01 & -.02 & -.01 \\
\hline
\end{tabular}

American, 2 = American Indian, 3

= Native Hawaiian, 4 = Two or

more races and $5=$ Other)

13. Sex ( 0 for male and 1 for female) 
Table 3

Bivariate Correlations $(n=81)$

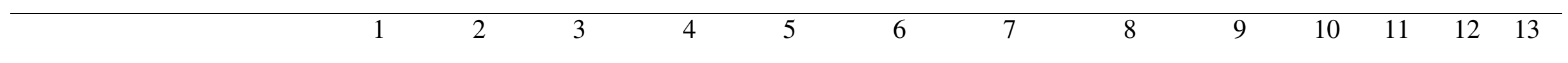

1. Physical activity

2. Domain self-efficacy

3. Support from entire social

network

4. Support from family

5. Support from friends

6. Esteem support from entire

social network

7. Informational support from

.18

.12

$$
.81 * * *
$$

$.72 * * * .67 * * *$

$.41 * * * \quad-$

entire social network

8. Companionship support $.25 *$ $.31 *$

$.88 * * *$

$.79 * *$

$.72 * * *$

$.57 * * *$

$.65 * * *-$

from entire social network

9. Positive social exchanges
$.37 * *$
$.45 * * \quad .59 * * *$

$.54 * * *$

$.45 * * * \quad .51 * * * \quad-$ 


\begin{tabular}{|c|c|c|c|c|c|c|c|c|c|c|c|}
\hline 10. Negative social exchanges & -.16 & $-.51 * * *$ & -.03 & .01 & -.06 & -.15 & .07 & .02 & $-.33^{*}$ & - & \\
\hline 11. Age & .21 & .07 & -.11 & -.08 & -.10 & -.03 & -.17 & -.07 & -.12 & -.08 & - \\
\hline 12. Race $(0=$ White, $1=$ & -.03 & .01 & -.10 & -.07 & -.10 & -.05 & -.09 & -.12 & -.11 & .01 & -.15 \\
\hline
\end{tabular}

African American, 2 =

American Indian, 3 = Native

Hawaiian, 4 = Two or more

races and $5=$ Other)

13. Sex ( 0 for male and 1 for female) 
Appendix A: The Physical Activity Subscale of the HPLP-II

Indicate the frequency with which you engage in $\quad$ Never $\quad$ Rarely Sometimes Routinely each behavior

1. Follow a planned exercise program.

12

2

3

4

2. Exercise vigorously for 20 or more minutes at

1

2

3

4

least three times a week.

3. Take part in light to moderate physical activity

12

2

3

4

4. Take part in leisure-time (recreational) physical

1

2

3

4 activities.

5. Do stretching exercises at least 3 times per week. $\quad 1 \quad 1 \quad 2 \quad 3 \quad 4$

6. Get exercise during usual daily activities.

1

2

3

4

7. Check my pulse rate when exercising.

12

3

4

8. Reach my target heart rate when exercising.

12

3

4 
Appendix B: The Evaluation Questionnaire

\begin{tabular}{|c|c|c|c|c|c|}
\hline The following questions address & Strongly Disagree & Mildly & Mildly & Agree & Strongly \\
\hline your future goal. Despite repetition & disagree & disagree & agree & & agree \\
\hline in the questions in this section, we & & & & & \\
\hline ask you to answer patiently, openly & & & & & \\
\hline
\end{tabular}

1. I am determined to fulfill my

12

3

4

5

6

future goals.

2. I believe that I will achieve my $\quad 1 \quad 20 \begin{array}{llllll} & 2 & 3 & 4 & 5\end{array}$

future goals.



for my future are realistic.

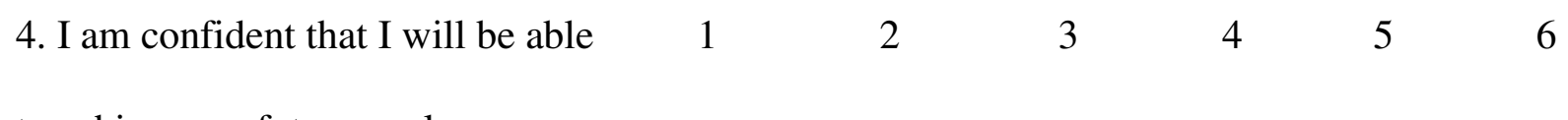

to achieve my future goals.

5. There are barriers that I may $\quad \begin{array}{lllllll} & 1 & 2 & 3 & 4 & 5 & 6\end{array}$

encounter that may prevent me

from achieving my future goals.

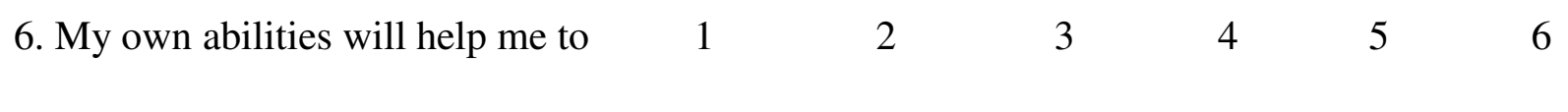
achieve my future goals.

Note. Question 5, which refers to barriers, was reversed coded to remain consistent with similar self-efficacy scales. 
Appendix C: The Positive Social Influence Scale

During the past 12 months, how often has $\quad \begin{array}{llllll}0 \text { - Never } & 1 & 2 & 3 & 4 \text { - Very often }\end{array}$

your family (that is, your spouse, siblings,

children, grandchildren, or other family

member):

1. Made plans with you for doing a physical

0

1

2

3

4 activity together?

2. Informed you about the expected

$0 \quad 1 \quad 2$

3

4

positive effects of a physical activity on

your health?

3. Complimented you on the mastery of a

0

12

3

4 physical activity skill?

4. Clarified for you how you may achieve

0

12

3

4 your health goals through physical activity?

5. Affirmed that you have done well in your

0

12

3

4

physical activity?

6. Told you that you should be proud of your

0

12

3

4

physical activity skills?

7. Teamed up with you to engage in a

0

12

3

4

physical activity together?

8. Suggested a physical activity program or

0

12

3

4 facility which might assist your health?

9. Shown respect for your versatility (i.e.

12

3

4 
range of abilities) in physical activity?

10. Explained to you about the amount or

0

12

3

4

intensity of physical activity necessary for

improving your health?

11. Given you helpful reminders to do a

0

12

3

4

physical activity together with them?

12. Praised you that your physical activity

1

2

3

4

level is superior to that of other people

your age?

13. Changed their schedules so you could do

0

123

4 a physical activity together with them?
14. Explained to you why physical activity is

0
1
3
4 important to improve your health?
15. Promised you that they would participate
0
$\begin{array}{llll}1 & 2 & 3 & 4\end{array}$ in a physical activity with you?


During the past 12 months, how often has $\quad \begin{array}{llllll}0 \text { - Never } & 1 & 2 & 3 & 4 \text { - Very often }\end{array}$ your friends (including a close friend, acquaintance, neighbor, coworker, or other person you would consider as a friend):

16. Made plans with you for doing a physical 0

1

2

3

4 activity together?

17. Informed you about the expected

$\begin{array}{lll}0 & 1 & 2\end{array}$

3

4 positive effects of a physical activity on your health?

18. Complimented you on the mastery of a 0 12 3

4 physical activity skill?

19. Clarified for you how you may achieve

0

12

3

4 your health goals through physical activity?

20. Affirmed that you have done well in your physical activity?

21. Told you that you should be proud of your physical activity skills?

22. Teamed up with you to engage in a

0

12

3 physical activity together?

23. Suggested a physical activity program or 0

$\begin{array}{llll}1 & 2 & 3 & 4\end{array}$
facility which might assist your health?

24. Shown respect for your versatility (i.e. 
range of abilities) in physical activity?

25. Explained to you about the amount or

intensity of physical activity necessary for improving your health?

26. Given you helpful reminders to do a physical activity together with them?

27. Praised you that your physical activity level is superior to that of other people your age?

28. Changed their schedules so you could do a physical activity together with them?

29. Explained to you why physical activity is important to improve your health?

30. Promised you that they would participate in a physical activity with you? $\begin{array}{lllll}0 & 1 & 2 & 3 & 4\end{array}$

$\begin{array}{llll}0 & 1 & 2 & 3\end{array}$

4

$\begin{array}{lllll}0 & 1 & 2 & 3 & 4\end{array}$

$\begin{array}{lllll}0 & 1 & 2 & 3 & 4\end{array}$

$\begin{array}{lllll}0 & 1 & 2 & 3 & 4\end{array}$

$\begin{array}{lllll}0 & 1 & 2 & 3 & 4\end{array}$

Note. Support from the entire social network was computed by averaging items 1 to 30, support from family was computed by averaging items 1 to 15 , support from friends was computed by averaging items 16 to 30 , companionship support from the entire social network was computed by averaging items $1,7,11,13,15,16,22,26,28$, and 30 , informational support from the entire social network was computed by averaging items $2,4,8,10,14,17,19,23,25$, and 29, and esteem support from the entire social network was computed by averaging items $3,5,6,9,12,18$, 20, 21, 24, and 27. 
Appendix D: Positive Social Exchanges Scale

In the past month, how often did the people Never Rarely $\quad$ Sometimes Often Very Often you know:

\begin{tabular}{lllllll}
\hline 1. Offer helpful advice when you needed to & 1 & 2 & 3 & 4 & 5
\end{tabular} make important decisions?

$\begin{array}{lllllll}\text { 2. Do favors and other things for you? } & 1 & 2 & 3 & 4 & 5\end{array}$

3. Do or say things that were kind or $\quad \begin{array}{llllll}1 & 2 & 3 & 4 & 5\end{array}$ considerate?

4. Provide you with good company and $\quad \begin{array}{llllll}1 & 2 & 3 & 4 & 5\end{array}$ companionship?

$\begin{array}{lllllll}\text { 5. Make useful suggestions? } & 1 & 2 & 3 & 4 & 5\end{array}$

$\begin{array}{lllllll}\text { 6. Provide you with aid and assistance? } & 1 & 2 & 3 & 4 & 5\end{array}$

$\begin{array}{lllllll}\text { 7. Cheer you up or help you feel better? } & 1 & 2 & 3 & 4 & 5\end{array}$

8. Include you in things they were doing? $\quad \begin{array}{llllll} & 1 & 2 & 3 & 4 & 5\end{array}$

9. Suggest ways that you could deal with $\quad \begin{array}{llllll}1 & 2 & 3 & 4 & 5\end{array}$

problems you were having?

10. Help you with an important task or $\quad \begin{array}{lllll}1 & 2 & 3 & 4 & 5\end{array}$ something that you could not do on your own?
11. Discuss your personal matters or
12
34
5 concerns with you?

12. Do social or recreational activities with $\quad \begin{array}{llllll}1 & 2 & 3 & 4 & 5\end{array}$ you? 
Appendix E: Negative Social Exchanges Scale

In the past month, how often did the people Never Rarely Sometimes Often Very Often you know:

1. Give you unwanted advice?

12

2

12

23

34

5

3. Leave you out of activities you would

12

3

4

5 have enjoyed?

4. Do things that were thoughtless or

1

2

3

4

5 inconsiderate?

5. Question or doubt your decisions?

12

6. Ask you for too much help?

1

2

12

7. Forget or ignore you?

8. Act angry or upset with you?

12

1

2

2

3

4

5

9. Interfere or meddle in your personal matters?

10. Fail to give you assistance that you

1

2

3

4

5 were counting on?

\begin{tabular}{|c|c|c|c|c|}
\hline 11. Fail to spend enough time with you? & 1 & 2 & 3 & 4 \\
\hline 12. Act unsympathetic or critical about & 1 & 2 & 3 & 4 \\
\hline
\end{tabular}


Appendix F: The Godin Leisure Time Exercise Questionnaire

During a typical 7-Day period (a week), how many times on the average do you do the following kinds of exercise for more than 15 minutes during your free time (write on each line the appropriate number):

1. Strenuous exercise (Heart beats rapidly; e.g., running, jogging, hockey,

football, soccer, squash, basketball, cross country skiing, judo, roller skating, vigorous swimming, vigorous long distance bicycling).

2. Moderate exercise (Not exhausting; e.g., fast walking, baseball, tennis, easy bicycling, volleyball, badminton, easy swimming, alpine skiing, popular and folk dancing).

3. Mild exercise (Minimal effort; e.g., yoga, archery, fishing from river bank, bowling, horseshoes, golf, snowmobiling, easy walking).

The Godin Leisure Time Exercise Questionnaire (Godin \& Shephard, 1997; 3 items) was used to assess participants' physical activity levels. Participants indicated how many times in a typical week they engaged in strenuous, moderate, and mild physical activity for more than 15 minutes. Responses were converted into metabolic equivalents by multiplying the occurrence of strenuous, moderate, and light physical activity by nine, five, and three, respectively, and summed $(M=$ 74.02, $S D=174.76$, Range $=0$ - 3270). Because the metabolic equivalents were positively skewed, participants' scores were transformed by logarithmic transformations. The logarithmic metabolic equivalents ranged from 0.48 to $3.51(M=1.73, S D=0.31)$. 
Appendix G: Multiple Hierarchical Linear Regressions Predicting HPLP-II $(n=403)$

Table G1

Multiple Hierarchical Linear Regression Predicting Physical Activity

\begin{tabular}{|c|c|c|c|c|c|}
\hline Predictor & $\Delta F$ & $\Delta R^{2}$ & $B$ & $S E$ & $\beta$ \\
\hline Step 1 & $F(3,386)=4.31, p<.05$ & .032 & & & \\
\hline Age & & & -0.02 & 0.02 & -.03 \\
\hline Race & & & -0.19 & 0.05 & $-.17 * *$ \\
\hline Sex & & & -0.03 & 0.08 & -.02 \\
\hline Step 2 & $F(1,385)=127.38, p<.001$ & .241 & & & \\
\hline Age & & & -0.01 & 0.02 & -.01 \\
\hline Race & & & -0.14 & 0.04 & $-.12 *$ \\
\hline Sex & & & -0.04 & 0.07 & -.02 \\
\hline Support from the entire & & & 0.37 & 0.03 & $.49 * * *$ \\
\hline
\end{tabular}

Notes. Overall model: $F(4,385)=36.14, R^{2}=.273, p<.001 ; * p<.05, * * p=.001, * * * p<.001$

In regard to Hypothesis 1, a multiple hierarchical linear regression was conducted to determine whether participants who reported higher levels of support from the entire social network engaged in more physical activity after accounting for age, race, and sex. Age, race, and sex were included in Step 1 and were regressed onto physical activity. These variables accounted for $3.2 \%$ of the variance in physical activity, $F \Delta(3,386)=4.31, p<.05$. Next, support from the entire social network was included in Step 2, was regressed onto physical activity, and the overall model was significant $F(4,385)=36.14, p<.001$. Support from the entire social network accounted for an additional $24.1 \%$ of the variance in physical activity, $F \Delta(1,385)=127.38, p$ 
$<.001$. Examination of the standardized betas indicated that race $(\beta=-.12, p<.05)$ and emerging adults who reported higher levels of support from the entire social network $(\beta=.49, p$ $<.001)$ engaged in more physical activity. 
Table G2

Multiple Hierarchical Linear Regression Predicting Physical Activity

\begin{tabular}{|c|c|c|c|c|c|}
\hline Predictor & $\Delta F$ & $\Delta R^{2}$ & $B$ & $S E$ & $\beta$ \\
\hline Step 1 & $F(3,385)=4.27, p<.05$ & .032 & & & \\
\hline Age & & & -0.01 & 0.02 & -.03 \\
\hline Race & & & -0.19 & 0.05 & $-.17 * *$ \\
\hline Sex & & & -0.03 & 0.08 & -.02 \\
\hline Step 2 & $F(1,384)=17.80, p<.001$ & .043 & & & \\
\hline Age & & & -0.01 & 0.02 & -.02 \\
\hline Race & & & -0.19 & 0.05 & $-.17 * * *$ \\
\hline $\operatorname{Sex}$ & & & -0.05 & 0.08 & -.03 \\
\hline General self-efficacy & & & 1.12 & 0.26 & $.20 * * *$ \\
\hline Step 3 & $F(1,383)=115.38, p<.001$ & .214 & & & \\
\hline Age & & & 0.00 & 0.02 & .00 \\
\hline Race & & & -0.14 & 0.04 & $-.13 *$ \\
\hline Sex & & & -0.06 & 0.07 & -.03 \\
\hline General self-efficacy & & & 0.72 & 0.23 & $.13^{*}$ \\
\hline Support from the entire & & & 0.35 & 0.03 & $.47 * * *$ \\
\hline
\end{tabular}

Notes. Overall model: $F(5,383)=31.17, R^{2}=.289, p<.001 ; * p<.05, * * p=.001, * * * p<.001$

In regard to Hypothesis 2 and Exploratory Question 1, a multiple hierarchical linear regression was conducted to determine whether emerging adults who reported higher levels of 
general self-efficacy engaged in more physical activity after accounting for age, race, sex and whether support from the entire social network was associated with physical activity when accounting for general self-efficacy. Age, race, and sex were included in Step 1 and were regressed onto physical activity. These variables accounted for $3.2 \%$ of the variance in physical activity, $F \Delta(3,385)=4.27, p<.05$. Examination of the standardized betas indicated that race $(\beta$ $=-.17, p=.001$ ) was associated with physical activity. Next, general self-efficacy was included in Step 2, was regressed onto physical activity, and accounted for an additional $4.3 \%$ of the variance in physical activity, $F \Delta(1,384)=17.80, p<.001$. Examination of the standardized betas indicated that race $(\beta=-.17, p<.001)$ and emerging adults who reported higher levels of general self-efficacy engaged in more physical activity $(\beta=.20, p<.001)$. Thus, supporting Hypothesis 2. Finally, support from the entire social network was included in Step 3, was regressed onto physical activity, and the overall model was significant, $F(5,383)=31.17, p$ $<.001$. Support from the entire social network accounted for an addition $21.4 \%$ of the variance in physical activity, $F \Delta(1,383)=115.38, p<.001$. Examination of the standardized betas indicated that race $(\beta=-.13, p<.05)$, emerging adults who reported higher levels of general selfefficacy $(\beta=.13, p<.05)$, and emerging adults who reported higher levels of support from the entire social network $(\beta=.47, p<.001)$ engaged in more physical activity. 
Table G3

Multiple Hierarchical Linear Regression Predicting Physical Activity

\begin{tabular}{|c|c|c|c|c|c|}
\hline Predictor & $\Delta F$ & $\Delta R^{2}$ & $B$ & $S E$ & $\beta$ \\
\hline Step 1 & $F(3,385)=4.19, p<.05$ & .032 & & & \\
\hline Age & & & -0.01 & 0.02 & -.03 \\
\hline Race & & & -0.19 & 0.05 & $-.17 * *$ \\
\hline Sex & & & -0.02 & 0.08 & -.01 \\
\hline Step 2 & $F(2,383)=8.51, p<.001$ & .041 & & & \\
\hline Age & & & -0.01 & 0.02 & -.03 \\
\hline Race & & & -0.19 & 0.05 & $-.17 * *$ \\
\hline Sex & & & -0.07 & 0.08 & -.04 \\
\hline Positive social exchanges & & & 0.32 & 0.08 & $.19 * * *$ \\
\hline Negative social exchanges & & & -0.15 & 0.25 & -.03 \\
\hline
\end{tabular}

In regard to Hypothesis 3, a multiple hierarchical linear regression was conducted to determine whether emerging adults who perceived their interactions with the social network as positive engaged in more physical activity after accounting for age, race, and sex. Age, race, and sex were included in Step 1 and were regressed onto physical activity. These variables accounted for $3.2 \%$ of the variance in physical activity, $F \Delta(3,385)=4.19, p<.05$. Next, positive social exchanges and negative social exchanges were included in Step 2, were regressed onto physical activity, and the overall model was significant $F(5,383)=6.02, p<.001$. Positive social exchanges and negative social exchanges accounted for an additional $4.1 \%$ of the variance in 
physical activity, $F \Delta(2,383)=8.51, p<.001$. Examination of the standardized betas indicated that race $(\beta=-.17, p=.001)$ and emerging adults who perceived their interactions with others as positive $(\beta=.19, p<.001)$ engaged in more physical activity. 
Table G4

Multiple Hierarchical Linear Regression Predicting Physical Activity

\begin{tabular}{|c|c|c|c|c|c|}
\hline Predictor & $\Delta F$ & $\Delta R^{2}$ & $B$ & $S E$ & $\beta$ \\
\hline Step 1 & $F(3,386)=4.31, p<.05$ & .032 & & & \\
\hline Age & & & -0.02 & 0.02 & -.03 \\
\hline Race & & & -0.19 & 0.05 & $-.17 * *$ \\
\hline Sex & & & -0.03 & 0.08 & -.02 \\
\hline Step 2 & $F(2,384)=64.47, p<.001$ & .243 & & & \\
\hline Age & & & -0.01 & 0.02 & -.02 \\
\hline Race & & & -0.13 & 0.04 & $-.12 *$ \\
\hline Sex & & & -0.03 & 0.07 & -.02 \\
\hline Support from family & & & 0.14 & 0.03 & $.22 * * *$ \\
\hline Support from friends & & & 0.22 & 0.03 & $.33 * * *$ \\
\hline
\end{tabular}

In regard to Exploratory Question 2, a multiple hierarchical linear regression was conducted to examine the separate effects of reported social support from family and reported social support from friends on physical activity after accounting for age, race, and sex. Age, race, and sex were included in Step 1 and were regressed onto physical activity. These variables accounted for $3.2 \%$ of the variance in physical activity, $F \Delta(3,386)=4.31, p<.05$. Next, support from family and support from friends were included in Step 2 and were regressed onto physical activity. The overall model was significant $F(5,384)=29.23, p<.001$. These variables accounted for an additional $24.3 \%$ of the variance in physical activity, $F \Delta(2,384)=64.47, p$ 
$<.001$. Examination of the standardized betas indicated that race $(\beta=-.12, p<.05)$, emerging adults who reported higher levels of support from their family $(\beta=.22, p<.001)$, and emerging adults who reported higher levels of support from their friends $(\beta=.32, p<.001)$ engaged in more physical activity. 
Table G5

Multiple Hierarchical Linear Regression Predicting Physical Activity

\begin{tabular}{|c|c|c|c|c|c|}
\hline Predictor & $\Delta F$ & $\Delta R^{2}$ & $B$ & $S E$ & $\beta$ \\
\hline Step 1 & $F(3,386)=4.31, p<.05$ & .032 & & & \\
\hline Age & & & -0.02 & 0.02 & -.03 \\
\hline Race & & & -.019 & 0.05 & $-.17 * *$ \\
\hline Sex & & & -0.03 & 0.08 & -.02 \\
\hline Step 2 & $F(3,383)=62.27, p<.001$ & .317 & & & \\
\hline Age & & & 0.00 & 0.02 & .00 \\
\hline Race & & & -0.14 & 0.04 & $-.12 *$ \\
\hline Sex & & & 0.04 & 0.07 & .02 \\
\hline Companionship support from & & & 0.09 & 0.03 & $.13 *$ \\
\hline \multicolumn{6}{|l|}{ entire social network } \\
\hline Informational support from & & & -0.05 & 0.03 & -.07 \\
\hline \multicolumn{6}{|l|}{ entire social network } \\
\hline Esteem support from entire & & & 0.29 & 0.03 & $.51 * * *$ \\
\hline
\end{tabular}

Notes. Overall model: $F(6,383)=34.32, R^{2}=.349, p<.001 ; * p<.05, * * p=.001, * * * p<.001$

In regard to Exploratory Question 3, a multiple hierarchical linear regression was conducted to examine the separate effects of reported esteem support, informational support, and companionship support from the entire social network on physical activity after accounting for age, race, and sex. Age, race, and sex were included in Step 1 and were regressed onto physical 
activity. These variables accounted for $3.2 \%$ of the variance in physical activity, $F \Delta(3,386)=$ 4.31, $p<.05$. Next, companionship support, informational support, and esteem support from the entire social network were included in Step 2 and were regressed onto physical activity. The overall model was significant $F(6,383)=34.32, p<.001$ and accounted for an additional $31.7 \%$ of the variance in physical activity, $F \Delta(3,383)=62.27, p<.001$. Examination of the standardized betas indicated that race $(\beta=-.12, p<.05)$, emerging adults who reported higher levels of companionship support from the entire social network $(\beta=.13, p<.05)$, and emerging adults who reported higher levels of esteem support from the entire social network $(\beta=.51, p$ $<.001)$ engaged in more physical activity. 
Table G6

Multiple Hierarchical Linear Regression Predicting Physical Activity

\begin{tabular}{clcccc}
\hline Predictor & $\Delta F$ & $\Delta R^{2}$ & $B$ & $S E$ & $\beta$ \\
\hline Step 1 & $F(3,386)=4.26, p<.05$ & .032 & & & \\
Age & & -0.01 & 0.02 & -.03 \\
Race & & -0.19 & 0.05 & $-.17 * *$ \\
Sex & & -0.03 & 0.08 & -.02
\end{tabular}

Step 2

$F(6,379)=30.63, p<.001 \quad .316$

Age

$0.00 \quad 0.02 \quad .00$

Race

$-0.13 \quad 0.04-.12 *$

$\operatorname{Sex}$

$0.04 \quad 0.07 \quad .02$

Companionship support from

$0.03 \quad 0.03 \quad .05$

family

Informational support from

$\begin{array}{lll}-0.01 & 0.03 & -.02\end{array}$

family

Esteem support from family

$\begin{array}{lll}0.10 & 0.03 \quad .20 *\end{array}$

Companionship support from

$\begin{array}{lll}0.05 & 0.03 \quad .10\end{array}$

friends

Informational support from

$\begin{array}{lll}-0.04 & 0.03 \quad-.06\end{array}$

friends

Esteem support from friends

$\begin{array}{lll}0.18 & 0.04 & .34 * * *\end{array}$

Notes. Overall model: $F(9,379)=22.50, R^{2}=.348, p<.001 ; * p<.05, * * p=.001, * * * p<.001$ 
A multiple hierarchical linear regression was conducted to examine the effects of esteem support from family, companionship support from family, informational support from family, esteem support from friends, companionship support from friends, and information support from friends on physical activity after accounting for age, race, and sex. Age, race, and sex were included in Step 1 and were regressed onto physical activity. These variables accounted for 3.2\% of the variance in physical activity, $F \Delta(3,386)=4.26, p<.05$. Next, companionship support from family, informational support from family, esteem support from family, companionship support from friends, informational support from friends, and esteem support from friends were included in Step 2 and were regressed onto physical activity. The overall model was significant $F(9,379)=22.50, p<.001$ and accounted for an additional $31.6 \%$ of the variance in physical activity, $F \Delta(6,379)=30.63, p<.001$. Examination of the standardized betas indicated that race $(\beta=-.12, p<.05)$, emerging adults who reported higher levels of esteem support from family $(\beta$ $=.20, p<.05)$, and emerging adults who reported higher levels of esteem support from friends $(\beta$ $=.34, p<.001)$ engaged in more physical activity. 
Appendix H: Multiple Hierarchical Linear Regressions Predicting HPLP-II $(n=81)$

Table H1

Multiple Hierarchical Linear Regression Predicting Physical Activity

\begin{tabular}{|c|c|c|c|c|c|}
\hline Predictor & $\Delta F$ & $\Delta R^{2}$ & $B$ & $S E$ & $\beta$ \\
\hline Step 1 & $F(3,75)=1.77, p=.15$ & .066 & & & \\
\hline Age & & & .12 & 0.06 & .20 \\
\hline Race & & & 0.00 & 0.11 & .00 \\
\hline Sex & & & 0.33 & 0.26 & .14 \\
\hline Step 2 & $F(1,74)=10.00, p<.05$ & .111 & & & \\
\hline Age & & & 0.10 & 0.06 & .17 \\
\hline Race & & & -0.01 & 0.10 & -.01 \\
\hline Sex & & & 0.29 & 0.25 & .12 \\
\hline Domain self-efficacy & & & 1.65 & 0.52 & $.33^{*}$ \\
\hline Step 3 & $F(1,73)=9.88, p<.05$ & .098 & & & \\
\hline Age & & & 0.14 & 0.06 & $.23^{*}$ \\
\hline Race & & & 0.03 & 0.09 & .03 \\
\hline Sex & & & 0.17 & 0.23 & .07 \\
\hline Domain self-efficacy & & & 1.09 & 0.52 & $.22 *$ \\
\hline Support from the entire & & & 0.26 & 0.08 & $.34 *$ \\
\hline social network & & & & & \\
\hline
\end{tabular}

Notes. Overall model: $F(5,73)=5.55, R^{2}=.275, p<.001 ; * p<.05, * * p=.001, * * * p<.001$ 
In regard to Hypothesis 2 and Exploratory Question 1, a multiple hierarchical linear regression was conducted to determine whether emerging adults who reported higher levels of domain self-efficacy engaged in more physical activity after accounting for age, race, sex and whether support from the entire social network was associated with physical activity when accounting for domain self-efficacy. Age, race, and sex were included in Step 1 and were regressed onto physical activity. These variables did not significantly accounted for variance in physical activity. Next, domain self-efficacy was included in Step 2, was regressed onto physical activity, and accounted for an additional $11.1 \%$ of the variance in physical activity, $F \Delta(1,74)=$ $10.00, p<.05$. Examination of the standardized betas indicated that emerging adults who reported higher levels of domain self-efficacy engaged in more physical activity $(\beta=.33, p$ $<.001)$. Finally, support from the entire social network was included in Step 3, was regressed onto physical activity, and the overall model was significant, $F(5,73)=5.55, p<.001$. Support from the entire social network accounted for an addition $9.8 \%$ of the variance in physical activity, $F \Delta(1,73)=9.88, p<.05$. Examination of the standardized betas indicated that age $(\beta=.23, p$ $<.05)$, emerging adults who reported higher levels of domain self-efficacy $(\beta=.22, p<.05)$, and emerging adults who reported higher levels of support from the entire social network $(\beta=.34, p$ $<.05)$ engaged in more physical activity. 
Appendix I: Multiple Hierarchical Linear Regressions Predicting Godin Leisure Time Exercise Questionnaire $(n=403)$

Table I1

Bivariate Correlations $(n=403)$

$\begin{array}{lllllllllllll}1 & 2 & 3 & 4 & 5 & 6 & 7 & 8 & 9 & 10 & 11 & 12 & 13\end{array}$

1. Physical activity

2. General self-efficacy

$.12 * \quad-$

3. Support from entire social

$.29 * * \quad .16^{*} \quad-$

network

4. Support from family

$.24 * * .14 * \quad .88 * * \quad-$

5. Support from friends

$.28 * * \quad .13 * \quad .88 * * \quad .56 * * \quad-$

6. Esteem support from entire

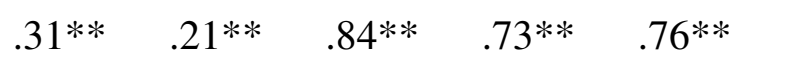

social network

7. Informational support from

.16

.05

$.81 *$

$.72 * *$

$.72 * * \quad .49 * * \quad-$

entire social network

8. Companionship support from $\quad .26 * * \quad .12 * \quad .86 * * \quad .79 * * \quad .73 * * \quad .59 * * \quad .60 * * \quad-$

entire social network 


\begin{tabular}{|c|c|c|c|c|c|c|c|c|c|c|c|c|}
\hline 9. Positive social exchanges & -.01 & $.29 * *$ & $.41 * *$ & $.35^{* *}$ & $.37 * *$ & $.36 * *$ & $.32 * *$ & $.35^{* *}$ & - & & & \\
\hline 10. Negative social exchanges & .00 & $-.23 * *$ & -.01 & .00 & -.02 & -.05 & .03 & .00 & $-.28 * *$ & - & & \\
\hline 11. Age & -.04 & -.06 & -.03 & -.06 & .00 & -.03 & -.01 & -.03 & -.04 & -.09 & - & \\
\hline 12. Race $(0=$ White, $1=$ African & -.05 & .01 & -.09 & -.03 & $-.12 *$ & -.08 & -.06 & -.08 & -.01 & -.02 & -.01 & - \\
\hline \multicolumn{13}{|l|}{ American, $2=$ American Indian, 3} \\
\hline \multicolumn{13}{|l|}{$=$ Native Hawaiian, $4=$ Two or } \\
\hline \multicolumn{13}{|l|}{ more races and $5=$ Other) } \\
\hline 13. Sex ( 0 for male and 1 for & -.02 & .07 & .01 & .07 & -.05 & -.08 & .08 & .06 & $.15^{*}$ & .07 & -.08 & .00 \\
\hline
\end{tabular}


Table I2

Multiple Hierarchical Linear Regression Predicting Physical Activity

\begin{tabular}{|c|c|c|c|c|c|}
\hline Predictor & $\Delta F$ & $\Delta R^{2}$ & $B$ & $S E$ & $\beta$ \\
\hline Step 1 & $F(3,386)=0.58, p=.62$ & .005 & & & \\
\hline Age & & & & 0.01 & -.03 \\
\hline Race & & & -0.18 & 0.03 & -.03 \\
\hline Sex & & & -0.03 & 0.04 & -.03 \\
\hline Step 2 & $F(1,367)=33.87, p<.001$ & .084 & & & \\
\hline Age & & & 0.00 & 0.01 & -.03 \\
\hline Race & & & 0.00 & 0.02 & .00 \\
\hline Sex & & & -0.03 & 0.04 & -.04 \\
\hline Support from the entire & & & 0.10 & 0.01 & $.29 * * *$ \\
\hline social network & & & & & \\
\hline
\end{tabular}

Notes. Overall model: $F(4,367)=8.94, R^{2}=.089, p<.001 ; * p<.05, * * p=.001, * * * p<.001$

In regard to Hypothesis 1, a multiple hierarchical linear regression was conducted to determine whether participants who reported higher levels of support from the entire social network engaged in more physical activity after accounting for age, race, and sex. Age, race, and sex were included in Step 1 and were regressed onto physical activity. These variables did not significantly account for variance in physical activity. Next, support from the entire social network was included in Step 2, was regressed onto physical activity, and the overall model was significant $F(4,367)=8.94, p<.001$. Support from the entire social network accounted for an additional $8.4 \%$ of the variance in physical activity, $F \Delta(1,367)=33.87, p<.001$. Examination 
of the standardized betas indicated that emerging adults who reported higher levels of support from the entire social network $(\beta=.29, p<.001)$ engaged in more physical activity. 
Table I3

Multiple Hierarchical Linear Regression Predicting Physical Activity

\begin{tabular}{|c|c|c|c|c|c|}
\hline Predictor & $\Delta F$ & $\Delta R^{2}$ & $B$ & $S E$ & $\beta$ \\
\hline Step 1 & $F(3,367)=0.67, p=.63$ & .005 & & & \\
\hline Age & & & -0.01 & 0.01 & -.04 \\
\hline Race & & & -0.01 & 0.03 & -.03 \\
\hline Sex & & & -0.03 & 0.04 & -.04 \\
\hline Step 2 & $F(1,366)=5.93, p<.05$ & .016 & & & \\
\hline Age & & & -0.01 & 0.01 & -.03 \\
\hline Race & & & -0.02 & 0.03 & -.04 \\
\hline Sex & & & -0.04 & 0.04 & -.04 \\
\hline General self-efficacy & & & 0.34 & 0.14 & $.12 *$ \\
\hline Step 3 & $F(1,365)=29.86, p<.001$ & .074 & & & \\
\hline Age & & & 0.00 & 0.01 & -.02 \\
\hline Race & & & 0.00 & 0.02 & -.01 \\
\hline Sex & & & -0.04 & 0.04 & -.04 \\
\hline General self-efficacy & & & 0.22 & 0.13 & .08 \\
\hline Support from the entire & & & 0.10 & 0.01 & $.27 * * *$ \\
\hline
\end{tabular}

Notes. Overall model: $F(5,365)=7.62, R^{2}=.095, p<.001 ;{ }^{*} p<.05,{ }^{*} p=.001,{ }^{*} * * p<.001$

In regard to Hypothesis 2 and Exploratory Question 1, a multiple hierarchical linear regression was conducted to determine whether emerging adults who reported higher levels of 
general self-efficacy engaged in more physical activity after accounting for age, race, sex and whether support from the entire social network was associated with physical activity when accounting for general self-efficacy. Age, race, and sex were included in Step 1 and were regressed onto physical activity. These variables did not significantly account for variance in physical activity. Next, general self-efficacy was included in Step 2, was regressed onto physical activity, and accounted for $1.6 \%$ of the variance in physical activity, $F \Delta(1,366)=5.93, p<.05$. Examination of the standardized betas indicated that emerging adults who reported higher levels of general self-efficacy $(\beta=-.12, p<.05)$ engaged in more physical activity. Thus, supporting Hypothesis 2. Finally, support from the entire social network was included in Step 3, was regressed onto physical activity, and the overall model was significant, $F(5,365)=7.62, p$ $<.001$. Support from the entire social network accounted for an addition $7.4 \%$ of the variance in physical activity, $F \Delta(1,365)=29.86, p<.001$. Examination of the standardized betas indicated that emerging adults who reported higher levels of support from the entire social network $(\beta$ $=.27, p<.001)$ engaged in more physical activity. 
Table I4

Multiple Hierarchical Linear Regression Predicting Physical Activity

\begin{tabular}{|c|c|c|c|c|c|}
\hline Predictor & $\Delta F$ & $\Delta R^{2}$ & $B$ & $S E$ & $\beta$ \\
\hline Step 1 & $F(3,366)=0.54, p=.65$ & .004 & & & \\
\hline Age & & & -0.01 & 0.01 & -.04 \\
\hline Race & & & -0.01 & 0.03 & -.03 \\
\hline Sex & & & -0.03 & 0.04 & -.04 \\
\hline Step 2 & $F(2,364)=0.06, p=.93$ & .000 & & & \\
\hline Age & & & -0.01 & 0.01 & -.05 \\
\hline Race & & & -0.01 & 0.03 & -.03 \\
\hline Sex & & & -0.02 & 0.04 & -.03 \\
\hline Positive social exchanges & & & -0.01 & 0.04 & -.01 \\
\hline Negative social exchanges & & & -0.03 & 0.13 & -.01 \\
\hline
\end{tabular}

In regard to Hypothesis 3, a multiple hierarchical linear regression was conducted to determine whether emerging adults who perceived their interactions with the social network as positive engaged in more physical activity after accounting for age, race, and sex. Age, race, and sex were included in Step 1 and were regressed onto physical activity. These variables did not significantly account for variance in physical activity. Next, positive social exchanges and negative social exchanges were included in Step 2, were regressed onto physical activity, and the overall model was not significant. Positive social exchanges and negative social exchanges did not significantly account for variance in physical activity. 
Table I5

Multiple Hierarchical Linear Regression Predicting Physical Activity

\begin{tabular}{|c|c|c|c|c|c|}
\hline Predictor & $\Delta F$ & $\Delta R^{2}$ & $B$ & $S E$ & $\beta$ \\
\hline Step 1 & $F(3,368)=0.58, p=.62$ & .005 & & & \\
\hline Age & & & -0.01 & 0.01 & -.05 \\
\hline Race & & & -0.01 & 0.03 & -.03 \\
\hline Sex & & & -0.03 & 0.04 & -.03 \\
\hline Step 2 & $F(2,366)=17.30, p<.001$ & .086 & & & \\
\hline Age & & & -0.01 & 0.01 & -.03 \\
\hline Race & & & 0.00 & 0.02 & .00 \\
\hline Sex & & & -0.03 & 0.04 & -.03 \\
\hline Support from family & & & 0.03 & 0.02 & .12 \\
\hline Support from friends & & & 0.07 & 0.02 & $.20 * *$ \\
\hline
\end{tabular}

In regard to Exploratory Question 2, a multiple hierarchical linear regression was conducted to examine the separate effects of reported social support from family and reported social support from friends on physical activity after accounting for age, race, and sex. Age, race, and sex were included in Step 1 and were regressed onto physical activity. These variables did not significantly account for variance in physical activity. Next, support from family and support from friends were included in Step 2 and were regressed onto physical activity. The overall model was significant $F(5,366)=7.30, p<.001$. These variables accounted for an additional $0.86 \%$ of the variance in physical activity, $F \Delta(2,366)=17.30, p<.001$. Examination of the 
standardized betas indicated that emerging adults who reported higher levels of support from their friends $(\beta=.20, p=.001)$ engaged in more physical activity. 
Table I6

Multiple Hierarchical Linear Regression Predicting Physical Activity

\begin{tabular}{|c|c|c|c|c|c|}
\hline Predictor & $\Delta F$ & $\Delta R^{2}$ & $B$ & $S E$ & $\beta$ \\
\hline Step 1 & $F(3,368)=0.58, p=.62$ & .005 & & & \\
\hline Age & & & -0.01 & 0.01 & -.05 \\
\hline Race & & & -0.01 & 0.03 & -.03 \\
\hline Sex & & & -0.03 & 0.04 & -.03 \\
\hline Step 2 & $F(3,365)=14.47, p<.001$ & .106 & & & \\
\hline Age & & & 0.00 & 0.01 & -.02 \\
\hline Race & & & 0.00 & 0.02 & -.01 \\
\hline Sex & & & -0.01 & 0.04 & -.01 \\
\hline Companionship support from & & & 0.05 & 0.02 & $.15^{*}$ \\
\hline entire social network & & & & & \\
\hline Informational support from & & & -0.02 & 0.02 & -.06 \\
\hline entire social network & & & & & \\
\hline Esteem support from entire & & & 0.07 & 0.01 & $.25^{* * *}$ \\
\hline
\end{tabular}

Notes. Overall model: $F(6,365)=7.56, R^{2}=.111, p<.001 ;{ }^{*} p<.05, * * p=.001,{ }^{* * *} p<.001$

In regard to Exploratory Question 3, a multiple hierarchical linear regression was conducted to examine the separate effects of reported esteem support, informational support, and companionship support from the entire social network on physical activity after accounting for age, race, and sex. Age, race, and sex were included in Step 1 and were regressed onto physical 
activity. These variables did not significantly account for variance in physical activity. Next, companionship support, informational support, and esteem support from the entire social network were included in Step 2 and were regressed onto physical activity. The overall model was significant $F(6,365)=7.56, p<.001$ and accounted for an additional $10.6 \%$ of the variance in physical activity, $F \Delta(3,365)=14.47, p<.001$. Examination of the standardized betas indicated that emerging adults who reported higher levels of companionship support from the entire social network $(\beta=.15, p<.05)$ and emerging adults who reported higher levels of esteem support from the entire social network $(\beta=.25, p<.001)$ engaged in more physical activity. 
Table I7

Multiple Hierarchical Linear Regression Predicting Physical Activity

\begin{tabular}{llllll}
\hline Predictor & $\Delta F$ & $\Delta R^{2}$ & $B$ & $S E$ & $\beta$ \\
\hline Step 1 & $F(3,367)=0.57, p=.63$ & .005 & & & \\
Age & & -0.01 & 0.01 & -.04 \\
Race & & -0.01 & 0.03 & -.03 \\
Sex & & -0.03 & 0.04 & -.03
\end{tabular}

Step 2

$F(6,361)=7.73, p<.001 \quad .113$

Age

$0.00 \quad 0.01 \quad-.02$

Race

$0.00 \quad 0.02 \quad-.01$

Sex

$\begin{array}{lll}-0.01 & 0.04 & -.01\end{array}$

Companionship support from

$0.00 \quad 0.01 \quad .02$

family

Informational support from

$\begin{array}{lll}-0.01 & 0.02 & -.04\end{array}$

family

Esteem support from family

$0.05 \quad 0.02 \quad .20 *$

Companionship support from

$0.05 \quad 0.02 \quad .18^{*}$

friends

Informational support from

$\begin{array}{lll}0.00 & 0.02 & -.03\end{array}$

friends

Esteem support from friends

$\begin{array}{lll}0.13 & 0.02 \quad .04\end{array}$

Notes. Overall model: $F(9,361)=5.37, R^{2}=.108, p<.001 ; * p<.05, * * p=.001, * * * p<.001$ 
A multiple hierarchical linear regression was conducted to examine the effects of esteem support from family, companionship support from family, informational support from family, esteem support from friends, companionship support from friends, and information support from friends on physical activity after accounting for age, race, and sex. Age, race, and sex were included in Step 1 and were regressed onto physical activity. These variables did not significantly account for variance in physical activity. Next, companionship support from family, informational support from family, esteem support from family, companionship support from friends, informational support from friends, and esteem support from friends were included in Step 2 and were regressed onto physical activity. The overall model was significant $F(99,361)=$ $5.37, p<.001$ and accounted for an additional $11.3 \%$ of the variance in physical activity, $F \Delta(6$, $361)=7.73, p<.001$. Examination of the standardized betas indicated that emerging adults who reported higher levels of esteem support from family $(\beta=.20, p<.05)$ and emerging adults who reported higher levels of companionship support from friends $(\beta=.18, p<.05)$ engaged in more physical activity. 
Appendix J: Multiple Hierarchical Linear Regressions Predicting Godin Leisure Time Exercise Questionnaire $(n=81)$

Table J1

Bivariate Correlations $(n=81)$

$\begin{array}{llllllllllllll}1 & 2 & 3 & 4 & 5 & 6 & 7 & 8 & 9 & 10 & 11 & 12 & 13\end{array}$

1. Physical activity

2. Domain self-efficacy .21

3. Support from entire social

$.27 * \quad .33^{*}$

network

4. Support from family $.27 * \quad .23 * \quad .85^{* * *} \quad-$

5. Support from friends

$.22 \quad .33^{*} \quad .85^{* * *} \quad .46^{* * *}-$

6. Esteem support from entire

$.35 * * \quad .36 * *$

$.81 * * * \quad .64 * * * \quad .74 * * * \quad-$

social network

7. Informational support from

entire social network

8. Companionship support from $\quad .14 \quad .31 * \quad \begin{array}{lllllll} & .88 * * & .79 * * & .72 * * * & .57 * * * & .65 * * * & -\end{array}$

entire social network 


\begin{tabular}{|c|c|c|c|c|c|c|c|c|c|c|c|c|c|}
\hline 9. Positive social exchanges & .18 & $.43 * * *$ & $.60 * * *$ & $.45^{* *}$ & $.59 * * *$ & $.54 * * *$ & $.45^{* * *}$ & $.51 * * *$ & - & & & & \\
\hline 10. Negative social exchanges & -.07 & $-.51 * * *$ & -.03 & .01 & -.06 & -.15 & .07 & .02 & $-.33 *$ & - & & & \\
\hline 11. Age & .03 & .07 & -.11 & -.08 & -.10 & -.03 & -.17 & -.07 & -.12 & -.08 & - & & \\
\hline 12. Race $(0=$ White, $1=$ African & -.03 & .01 & -.10 & -.07 & -.10 & -.05 & -.09 & -.12 & -.11 & .01 & -.15 & - & \\
\hline \multicolumn{13}{|l|}{ American, $2=$ American Indian, } & \\
\hline \multicolumn{14}{|l|}{$3=$ Native Hawaiian, $4=$ Two or } \\
\hline \multicolumn{14}{|l|}{ more races and $5=$ Other) } \\
\hline 13. $\operatorname{Sex}(0=$ Male, $1=$ Female $)$ & -.10 & .06 & .15 & .20 & .04 & -.01 & .22 & .19 & .17 & .07 & -.05 & .05 & - \\
\hline
\end{tabular}


Table J2

Multiple Hierarchical Linear Regression Predicting Physical Activity

\begin{tabular}{|c|c|c|c|c|c|}
\hline Predictor & $\Delta F$ & $\Delta R^{2}$ & $B$ & $S E$ & $\beta$ \\
\hline Step 1 & $F(3,70)=0.29, p=.82$ & .013 & & & \\
\hline Age & & & .12 & 0.06 & .20 \\
\hline Race & & & 0.00 & 0.11 & .00 \\
\hline Sex & & & 0.33 & 0.26 & .14 \\
\hline Step 2 & $F(1,69)=3.93, p=.05$ & .053 & & & \\
\hline Age & & & 0.10 & 0.06 & .17 \\
\hline Race & & & -0.01 & 0.10 & -.01 \\
\hline Sex & & & 0.29 & 0.25 & .12 \\
\hline Domain self-efficacy & & & 1.65 & 0.52 & $.33 *$ \\
\hline Step 3 & $F(1,68)=3.25, p=.07$ & .043 & & & \\
\hline Age & & & 0.14 & 0.06 & $.23 *$ \\
\hline Race & & & 0.03 & 0.09 & .03 \\
\hline Sex & & & 0.17 & 0.23 & .07 \\
\hline Domain self-efficacy & & & 1.09 & 0.52 & $.22 *$ \\
\hline Support from the entire & & & 0.26 & 0.08 & $.34 *$ \\
\hline
\end{tabular}

Notes. Overall model: $F(5,68)=1.65, R^{2}=.109, p=.15 ; * p<.05, * * p=.001, * * * p<.001$

In regard to Hypothesis 2 and Exploratory Question 1, a multiple hierarchical linear regression was conducted to determine whether emerging adults who reported higher levels of 
domain self-efficacy engaged in more physical activity after accounting for age, race, sex and whether support from the entire social network uniquely was associated with physical activity when accounting for domain self-efficacy. Age, race, and sex were included in Step 1 and were regressed onto physical activity. These variables did not significantly account for variance in physical activity. Next, domain self-efficacy were included in Step 2, were regressed onto physical activity, and the overall model was not significant. Finally, support from the entire social network was included in Step 3, was regressed onto physical activity, and the overall model was not significant. Support from the entire social network did not significantly account for variance in physical activity. 
Appendix K: Multiple Hierarchical Liner Regressions Predicting HPLP-II and Controlling for

$$
\operatorname{BMI}(n=403)
$$

Table K1

Multiple Hierarchical Linear Regression Predicting Physical Activity

\begin{tabular}{|c|c|c|c|c|c|}
\hline Predictor & $\Delta F$ & $\Delta R^{2}$ & $B$ & $S E$ & $\beta$ \\
\hline Step 1 & $F(1,389)=6.63, p<.05$ & .017 & & & \\
\hline BMI & & & -0.01 & 0.00 & $-.12 *$ \\
\hline Step 2 & $\mathrm{~F}(1,388)=122.69, \mathrm{p}<.001$ & .236 & & & \\
\hline BMI & & & 0.00 & 0.00 & -.05 \\
\hline Support from the entire & & & 0.37 & 0.03 & $.49 * * *$ \\
\hline
\end{tabular}

Notes. Overall model: $F(2,388)=65.70, R^{2}=.253, p<.001 ; * p<.05, * * p=.001, * * * p<.001$

In regard to Hypothesis 1, a multiple hierarchical linear regression was conducted to determine whether participants who reported higher levels of support from the entire social network engaged in more physical activity after accounting for BMI. BMI was included in Step 1, was regressed onto physical activity, and accounted for $1.7 \%$ of the variance in physical activity, $F(1,389)=6.63, p<.05$. Examination of the standardized beta indicated that emerging adults who had higher BMIs $(\beta=-.12, p<.05)$ engaged in less physical activity. Next, support from the entire social network was included in Step 2, was regressed onto physical activity, and the overall model was significant $F(2,388)=65.70, p<.001$. Support from the entire social network accounted for an additional $23.6 \%$ of the variance in physical activity, $F \Delta(1,388)=122.69$, p $<.001$. Examination of the standardized betas indicated that emerging adults who reported 
higher levels of support from the entire social network $(\beta=.49, p<.001)$ engaged in more physical activity. 
Table K2

Multiple Hierarchical Linear Regression Predicting Physical Activity

\begin{tabular}{|c|c|c|c|c|c|}
\hline Predictor & $\Delta F$ & $\Delta R^{2}$ & $B$ & $S E$ & $\beta$ \\
\hline Step 1 & $F(1,388)=6.35, p<.05$ & .016 & & & \\
\hline BMI & & & -0.01 & 0.00 & $-.12 *$ \\
\hline Step 2 & $F(1,387)=15.60, p<.001$ & .038 & & & \\
\hline BMI & & & -0.01 & 0.00 & $-.11 *$ \\
\hline General Self-efficacy & & & 1.06 & 0.26 & $.19 * * *$ \\
\hline Step 3 & $F(1,386)=112.50, p<.001$ & .213 & & & \\
\hline BMI & & & 0.00 & 0.00 & -.05 \\
\hline General Self-efficacy & & & 0.69 & 0.23 & $.12 *$ \\
\hline Support from the entire & & & 0.36 & 0.03 & $.47 * * *$ \\
\hline social network & & & & & \\
\hline
\end{tabular}

In regard to Hypothesis 2 and Exploratory Question 1, a multiple hierarchical linear regression was conducted to determine whether emerging adults who reported higher levels of general self-efficacy engaged in more physical activity after accounting for BMI. BMI was included in Step 1, was regressed onto physical activity, and accounted for $1.6 \%$ of the variance in physical activity, $F(1,388)=6.35, p<.05$. Examination of the standardized beta indicated that emerging adults who had higher BMIs $(\beta=-.12, p<.05)$ engaged in less physical activity. Next, general self-efficacy was included in Step 2, was regressed onto physical activity, and accounted for an additional $3.8 \%$ of the variance in physical activity, $F \Delta(1,387)=15.60, p$ 
$<.001$. Examination of the standardized betas indicated that emerging adults who had higher BMIs $(\beta=-.11, p<.05)$ engaged in less physical activity and emerging adults who reported higher levels of general self-efficacy engaged in more physical activity $(\beta=.19, p<.001)$. Thus, supporting Hypothesis 2. Finally, support from the entire social network was included in Step 3, was regressed onto physical activity, and the overall model was significant, $F(3,386)=47.03, p$ $<$.001. Support from the entire social network accounted for an addition $21.3 \%$ of the variance in physical activity, $F \Delta(1,386)=112.50, p<.001$. Examination of the standardized betas indicated that emerging adults who reported higher levels of general self-efficacy $(\beta=.12, p$ $<.05)$ and emerging adults who reported higher levels of support from the entire social network $(\beta=.47, p<.001)$ engaged in more physical activity. 
Table K3

Multiple Hierarchical Linear Regression Predicting Physical Activity

\begin{tabular}{|c|c|c|c|c|c|}
\hline Predictor & $\Delta F$ & $\Delta R^{2}$ & $B$ & $S E$ & $\beta$ \\
\hline Step 1 & $F(1,387)=6.20, p<.05$ & .016 & & & \\
\hline BMI & & & -0.01 & 0.00 & $-.12 *$ \\
\hline Step 2 & $F(2,385)=6.98, p=.001$ & .034 & & & \\
\hline BMI & & & -0.01 & 0.00 & -.09 \\
\hline Positive Social Exchanges & & & 0.29 & 0.08 & $.17 * *$ \\
\hline Negative Social Exchanges & & & -0.13 & 0.25 & -.02 \\
\hline
\end{tabular}

Notes. Overall model: $F(3,385)=6.78, R^{2}=.050, p<.001 ; * p<.05, * * p=.001, * * * p<.001$

In regard to Hypothesis 3, a multiple hierarchical linear regression was conducted to determine whether emerging adults who perceived their interactions with the social network as positive engaged in more physical activity after accounting for BMI. BMI was included in Step 1, was regressed onto physical activity, and accounted for $1.6 \%$ of the variance in physical activity, $F(1,387)=6.20, p<.05$. Examination of the standardized beta indicated that emerging adults who had higher BMIs $(\beta=-.12, p<.05)$ engaged in less physical activity. Next, positive social exchanges and negative social exchanges were included in Step 2, were regressed onto physical activity, and the overall model was significant $F(3,385)=6.78, p<.001$. Positive social exchanges and negative social exchanges accounted for an additional $3.4 \%$ of the variance in physical activity, $F \Delta(2,385)=6.98, p=.001$. Examination of the standardized betas indicated that emerging adults who perceived their interactions with others as positive $(\beta=.17, p<.001)$ engaged in more physical activity. 
Table K4

Multiple Hierarchical Linear Regression Predicting Physical Activity

\begin{tabular}{|c|c|c|c|c|c|}
\hline Predictor & $\Delta F$ & $\Delta R^{2}$ & $B$ & $S E$ & $\beta$ \\
\hline Step 1 & $F(1,389)=6.63, p<.05$ & .017 & & & \\
\hline BMI & & & -0.01 & 0.00 & $-.12^{*}$ \\
\hline Step 2 & $F(2,387)=61.74, p<.001$ & .238 & & & \\
\hline BMI & & & 0.00 & 0.00 & -.05 \\
\hline Support from family & & & 0.15 & 0.03 & $.23 * * *$ \\
\hline Support from friends & & & 0.22 & 0.03 & $.32 * * *$ \\
\hline
\end{tabular}

Notes. Overall model: $F(3,387)=44.06, R^{2}=.255, p<.001 ; * p<.05,{ }^{* *} p=.001, * * * p<.001$

In regard to Exploratory Question 2, a multiple hierarchical linear regression was conducted to examine the separate effects of reported social support from family and reported social support from friends on physical activity after accounting for BMI. BMI was included in Step 1, was regressed onto physical activity, and accounted for $1.7 \%$ of the variance in physical activity, $F(1,389)=6.63, p<.05$. Examination of the standardized beta indicated that emerging adults who had higher BMIs $(\beta=-.12, p<.05)$ engaged in less physical activity. Next, support from family and support from friends were included in Step 2 and were regressed onto physical activity. The overall model was significant $F(5,387)=44.06, p<.001$. These variables accounted for an additional $23.8 \%$ of the variance in physical activity, $F \Delta(2,387)=61.74, p$ $<.001$. Examination of the standardized betas indicated that emerging adults who reported higher levels of support from their family $(\beta=.23, p<.001)$, and emerging adults who reported higher levels of support from their friends $(\beta=.32, p<.001)$ engaged in more physical activity. 
Table K5

Multiple Hierarchical Linear Regression Predicting Physical Activity

\begin{tabular}{|c|c|c|c|c|c|}
\hline Predictor & $\Delta F$ & $\Delta R^{2}$ & $B$ & $S E$ & $\beta$ \\
\hline Step 1 & $F(1,389)=6.63, p<.05$ & .017 & & & \\
\hline BMI & & & -0.01 & 0.00 & $-.12 *$ \\
\hline Step 2 & $F(3,386)=59.36, p<.001$ & .310 & & & \\
\hline BMI & & & 0.00 & 0.00 & -.01 \\
\hline Companionship support & & & 0.09 & 0.03 & $.13^{*}$ \\
\hline \multicolumn{6}{|l|}{ from entire social network } \\
\hline Informational support from & & & -0.04 & 0.03 & -.06 \\
\hline \multicolumn{6}{|l|}{ entire social network } \\
\hline Esteem support from entire & & & 0.29 & 0.03 & $.51 * * *$ \\
\hline social network & & & & & \\
\hline
\end{tabular}

Notes. Overall model: $F(4,386)=46.93, R^{2}=.327, p<.001 ; * p<.05, * * p=.001, * * * p<.001$

In regard to Exploratory Question 3, a multiple hierarchical linear regression was conducted to examine the separate effects of reported esteem support, informational support, and companionship support from the entire social network on physical activity after accounting for BMI. BMI was included in Step 1, was regressed onto physical activity, and accounted for $1.7 \%$ of the variance in physical activity, $F(1,389)=6.63, p<.05$. Examination of the standardized beta indicated that emerging adults who had higher BMIs $(\beta=-.12, p<.05)$ engaged in less physical activity. Next, companionship support, informational support, and esteem support from the entire social network were included in Step 2 and were regressed onto physical activity. The 
overall model was significant $F(4,386)=46.93, p<.001$ and accounted for an additional $31.0 \%$ of the variance in physical activity, $F \Delta(3,386)=59.36, p<.001$. Examination of the standardized betas indicated that emerging adults who reported higher levels of companionship support from the entire social network $(\beta=.13, p<.05)$, and emerging adults who reported higher levels of esteem support from the entire social network $(\beta=.51, p<.001)$ engaged in more physical activity. 
Table K6

Multiple Hierarchical Linear Regression Predicting Physical Activity

\begin{tabular}{llllll}
\hline Predictor & $\Delta F$ & $\Delta R^{2}$ & $B$ & $S E$ & $\beta$ \\
\hline Step 1 & $F(1,388)=6.26, p<.05$ & .016 & & & \\
BMI & & & -0.01 & 0.00 & $-.12^{*}$
\end{tabular}

Step 2

$F(6,382)=29.18, p<.001 \quad .309$

BMI

$\begin{array}{lll}0.00 & 0.00 \quad .00\end{array}$

Companionship support from

$\begin{array}{lll}0.03 & 0.03 \quad .05\end{array}$

family

Informational support from

$\begin{array}{lll}0.00 & 0.03 & -.01\end{array}$

family

Esteem support from family

$0.11 \quad 0.03 \quad .21 *$

Companionship support from

$\begin{array}{lll}0.05 & 0.03 \quad .10\end{array}$

friends

Informational support from

$\begin{array}{lll}-0.03 & 0.03 & -.06\end{array}$

friends

Esteem support from friends

$0.18 \quad 0.04 \quad .33 * * *$

Notes. Overall model: $F(7,382)=26.29, R^{2}=.325, p<.001 ; * p<.05, * * p=.001, * * * p<.001$

A multiple hierarchical linear regression was conducted to examine the effects of esteem support from family, companionship support from family, informational support from family, esteem support from friends, companionship support from friends, and information support from friends on physical activity after accounting for BMI. BMI was included in Step 1, was regressed 
onto physical activity, and accounted for $1.7 \%$ of the variance in physical activity, $F(1,389)=$ $6.63, p<.05$. Examination of the standardized beta indicated that emerging adults who had higher BMIs $(\beta=-.12, p<.05)$ engaged in less physical activity. Next, companionship support from family, informational support from family, esteem support from family, companionship support from friends, informational support from friends, and esteem support from friends were included in Step 2 and were regressed onto physical activity. The overall model was significant $F(7,382)=26.29, p<.001$ and accounted for an additional $30.9 \%$ of the variance in physical activity, $F \Delta(6,382)=29.18, p<.001$. Examination of the standardized betas indicated that emerging adults who reported higher levels of esteem support from family $(\beta=.21, p<.05)$, and emerging adults who reported higher levels of esteem support from friends $(\beta=.33, p<.001)$ engaged in more physical activity. 